\title{
Origem e morfologia dos tanques naturais do Nordeste do Brasil
}

\author{
Felipe Rodrigues WALDHERR ${ }^{1}$, Hermínio Ismael de ARAÚJO-JÚNIOR² \& Sérgio Wilians de \\ Oliveira RODRIGUES ${ }^{3}$
}

1 Programa de Pós-graduação em Análise de Bacias e Faixas Móveis, Faculdade de Geologia, Universidade do Estado do Rio de Janeiro. Rua São Francisco Xavier, 524, Maracanã, CEP 20550-013, Rio de Janeiro, RJ, Brasil (felipewald@gmail.com).

2 Departamento de Estratigrafia e Paleontologia, Faculdade de Geologia, Universidade do Estado do Rio de Janeiro. Rua São Francisco Xavier, 524, Maracanã, CEP 20550-013, Rio de Janeiro, RJ, Brasil (herminio.ismael@yahoo.com.br).

3 Departamento de Geologia Regional e Geotectônica, Faculdade de Geologia, Universidade do Estado do Rio de Janeiro. Rua São Francisco Xavier, 524, Maracanã, CEP 20550-013, Rio de Janeiro, RJ, Brasil (swor@uerj.br).

Recebido em 12/2016. Aceito para publicação em 11/2017.

Versão online publicada em 16/3/2018 (www.pesquisasemgeociencias.ufrgs.br)

\begin{abstract}
Resumo - Os tanques naturais do Nordeste do Brasil têm sido amplamente analisados em termos paleontológicos. Entretanto, estudos relacionados à origem e morfologia dessas depressões naturais encontram-se estagnados desde a década de 1990. 0 presente trabalho tem como objetivo apresentar novas interpretações sobre a gênese desses tanques, bem como estabelecer uma nomenclatura correlacionável internacionalmente e propor uma classificação morfológica dessas feições. Foram consultados trabalhos acadêmicos elaborados desde o início do século XIX até artigos mais recentes, incluindo teses e dissertações, sobre a utilização do termo, a importância paleontológica e origem dos tanques naturais no nordeste brasileiro. Este trabalho propõe a utilização do termo tanque natural (raso e escarpado) para as cavidades naturais, de origens não-fluviais, sobre o embasamento cristalino, e manter o termo marmita, ou caldeirões, para aquelas de origem fluvial. Os modelos prévios para a origem dos tanques baseavam-se em três importantes situações, em ambiente subaéreo, para a formação dessas cavidades. Neste trabalho associa-se a corrosão química e a migração e concentração de cargas em subsuperfície como processos importantes para a gênese dos tanques naturais. Ao contrário da necessidade da superfície estar exposta para iniciar a formação da cavidade, o tanque pode ter sua origem e desenvolvimento associado ao ambiente subedáfico.
\end{abstract}

Palavras-chave: tanques naturais, megafauna do Quaternário, geomorfologia granítica, formas minoritárias do relevo.

Abstract - ORIGIN AND MORPHOLOGY OF NATURAL TANKS OF NORTHEASTERN BRAZIL. Natural tanks of Northeastern Brazil have been widely analyzed in paleontological terms. However, studies related to the origin and morphology of these natural depressions are stagnated since the 1990s. This work aims to present new interpretations about the origin of these tanks, as well as to establish an internationally correlated nomenclature and to propose a morphological classification of these features. Academic works elaborated from the beginning of the 19th century until more recent articles, including theses and dissertations, have been consulted on the application of the term, the paleontological importance and origin of the natural tanks in northeastern Brazil. We propose the use of the term natural tank (shallow and steeped) to depressions of non-fluvial origins on the bedrock, and maintain the term caldrons to those of fluvial origin. The previous models for the formation of natural tanks were based on three situations in subaerial environment. In this work, we associate the chemical corrosion and migration and concentration of charges in subsurface as important processes for the genesis of natural tanks. Instead of the necessity of the surface be exposed to start the formation of the cavity, the tank may have its origin and development associated with subedaphic environment.

Keywords: natural tanks, Quaternary megafauna, granite geomorphology, minor relief forms. 


\section{Introdução}

As primeiras referências sobre tanques naturais, na literatura acadêmica, datam do final do século XVIII (Fernandes et al., 2013a) e início do século XIX (Casal, 1817a, 1817b; Spix \& Martius, 1824). As primeiras expedições naturalistas e científicas que percorreram o nordeste brasileiro reaproveitaram o termo tanque (lato sensu) para denominar as áreas escavadas em depressões naturais sobre o embasamento cristalino, onde foram recuperados inúmeros fósseis de idade pleistocênica (Burlamaque, 1855, 1856; Hartt, 1870; Branner, 1902, 1915; Moraes, 1924, 1928). Atualmente o termo é utilizado no Nordeste do Brasil para denominar, de forma generalizada, as cavidades naturais encontradas no relevo granítico-gnáissico e, ocasionalmente, em rochas sedimentares (Mabesoone et al., 1990; Santos et al., 2002; Ximenes, 2003, 2009; Araújo-Júnior \& Porpino, 2011; Araújo-Júnior et al., 2011, 2013a, 2013b, 2015, 2016).

A partir da metade do século XIX, os tanques tornaram-se feições de enorme importância para a Paleontologia. Entre 1848 e 1862, o Museu Nacional empreendeu, por iniciativa de Frederico Burlamaque, custosas expedições que trouxeram ao Rio de Janeiro uma grande quantidade de fósseis da megafauna pleistocênica do Nordeste brasileiro, sendo a maior parte recuperada a partir dos depósitos de tanques (ver Fernandes et al., 2007, 2010, 2012). Além da possibilidade de reconstituição da paleofauna, os depósitos também permitiram uma análise sobre as condições paleoambientais e paleoecológicas que predominaram durante o Pleistoceno no Nordeste do Brasil (e.g. Paula-Couto, 1980; Bergqvist et al., 1997; Araújo-Júnior et al., 2015).

Embora muitos tanques (lato sensu) tenham sido analisados e descritos ao longo dos séculos, principalmente em termos de conteúdo fossilífero, pouco se tem discutido sobre os processos responsáveis pela sua origem. A partir da década de 1910 até meados dos anos 1990 os modelos propostos para a origem dos tanques (lato sensu) no Nordeste brasileiro apresentavam três situações: i) processo de evorsão; ii) o fator composicional do embasamento cristalino; e iii) a influência do sistema de fraturas e diáclases, sendo os dois últimos responsáveis pelo estabelecimento de áreas preferenciais ao intemperismo físico-químico em condições subaéreas (Branner, 1915; Moraes, 1924; Moraes Rêgo, 1926; Domingues, 1952; Paula-Couto, 1953; Rolim, 1974, 1982; Santos, 1982; Oliveira, 1989; Oliveira et al., 1989; Oliveira \& Hackspacher, 1989; Mabesoone \& Castro, 1975; Mabesoone et al., 1990). Entretanto, estudos recentes sobre a origem de feições similares aos tanques nordestinos (tanques, no lato sensu) em outros continentes têm associado essas formas ao trabalho de corrosão química ou à migração e concentração de cargas em subsuperfície (Twidale, 1989; Vidal Romaní, 1989; Campbell \& Twidale, 1995; Campbell, 1997; Vidal Romaní \& Twidale, 1998; Vidal Romaní \& Yepes Termiño, 2004; Twidale \& Vidal Romaní, 2005; Mayor Rodriguez, 2011). As pesquisas no meio acadêmico internacional têm atribuído um caráter polifásico, e inicialmente sob condições subedáficas, para a origem e desenvolvimento de cavidades sobre o embasamento cristalino.

0 presente trabalho busca trazer novas interpretações sobre a possível origem dos tanques (lato sensu) na região Nordeste do Brasil, utilizando estudos sobre feições análogas em outras partes do mundo, e formalizar a utilização do termo "tanque natural" (stricto sensu), com suas especificidades, na literatura acadêmica nacional. Uma análise morfológica foi utilizada a fim de elaborar uma possível classificação das cavidades encontradas sobre o embasamento cristalino, buscando facilitar o reconhecimento destas feições em atividades de campo. Desse modo, a finalidade deste trabalho é preencher a lacuna existente sobre a formação de tanques naturais no nordeste brasileiro.

\section{Histórico dos estudos sobre o tema}

\subsection{Propostas anteriores para a origem dos tanques}

As expedições científicas empreendidas por naturalistas europeus no Nordeste do Brasil, no início do século XIX, relatavam a presença de fósseis de "animais primitivos" encontrados em tanques e caldeirões escavados sobre as rochas cristalinas no interior da Bahia e de Alagoas (Casal, 1817a, 1817b; Spix \& Martius, 1824). 0 primeiro pesquisador a propor uma origem para os tanques descobertos foi o geólogo norte-americano Charles Frederick Hartt. Na obra intitulada Geologia e Geografia Física do Brasil (Hartt, 1870), Charles Hartt sugere que as cavidades encontradas hoje nas superfícies rochosas do sertão baiano estariam associadas a cachoeiras glaciais, da mesma forma como os pot-holes (traduzido para português, buracos) são encontrados hoje nas regiões de alta latitude da América do Norte. Entretanto, a hipótese de glaciação no Nordeste brasileiro durante o Cenozoico para formar enormes glaciares e quedas d'água associadas a esse tipo de ambiente não se sustenta, sendo então praticamente descartada.

Entre as décadas de 1910 e 1980, o principal 
modelo de origem e evolução dos tanques baseou-se na eficiência do processo de evorsão, ou seja, um tipo de abrasão provocada pelo movimento turbilhonar sobre o leito rochoso de rios (Branner, 1915; Moraes, 1924; Moraes Rêgo, 1926; Domingues, 1952; Paula-Couto, 1953; Rolim, 1974, 1982; Santos, 1982). O contínuo processo de escavação ao longo de um rio torrencial resultaria em depressões conhecidas atualmente como marmitas ou caldeirões. Estas formas estariam hoje expostas a condições climáticas bem distintas daquelas responsáveis pela sua formação.

Merece destaque o papel do geólogo estadunidense John Casper Branner, e sua importante contribuição sobre os processos químicos envolvidos na formação de um tanque natural (Branner, 1915). No livro intitulado Geologia Elementar, de 1915, Branner utiliza o termo caldeirão ao se referir às cavidades encontradas sobre a superfície rochosa. Entretanto, o autor distingue a forma em dois tipos, os caldeirões oriundos do desgaste do contato entre seixos e o fundo dos rios, como já citado anteriormente, e os caldeirões localizados em morros de granito, como os que ocorrem, por exemplo, nas vizinhanças de Quixadá, no Ceará, os quais teriam uma origem diferente. Segundo Branner (1915), nestes últimos a cavidade seria o resultado da ação química provocada diretamente pela estagnação de água em buracos na rocha. Assim, os minerais da rocha eram degradados, sendo transformados em lodo, e retirados da depressão por transbordamento através da entrada de novos fluxos de escoamento superficial e renovação das águas internas.

O trabalho de Oliveira \& Hackspacher (1989), realizado no oeste potiguar, esclarece que a ocorrência dos tanques não poderia representar trechos abandonados de leito fluvial, mas depressões originadas pelo trabalho erosivo, de caráter químico e físico, ao longo do sistema de fraturas e diáclases existentes no embasamento cristalino. Os autores reconheceram a importância da tectônica rúptil e do controle litoestrutural na formação e distribuição geográfica dos tanques.

Mabesoone et al. (1990) comentam que a maior parte dos tanques naturais do Rio Grande do Norte localizam-se sobre o embasamento granítico, em uma faixa contínua N-S, sendo observada também a presença de xenólitos de biotita-gnaisse e biotita-xisto. Os autores mencionam que os tanques ocorrem principalmente sobre inselbergs semicirculares e bastante fraturados. A direção dessas fraturas (NE-SW) teria sido responsável pela gênese da maioria dos tanques. No entanto, uma pequena quantidade dos tanques não segue o pa- drão estrutural NE-SW, e constitui forma subcircular, sendo sua origem atribuída à decomposição de mega-xenólitos. Em termos de comparação ao terreno granítico, os xenólitos são mais suscetíveis ao ataque intempérico em superfície devido à própria composição mineralógica, rica em biotita. Geralmente os xenólitos têm o formato circular ou oval e em conjunto ao intemperismo diferencial podem gerar cavidades. De acordo com os autores, o sistema de fraturas e diáclases observado em campo estaria associado às atividades tectônicas de caráter rúptil na época da Glaciação Riss (entre 140 ka e $200 \mathrm{ka}$ ), que posteriormente foram retrabalhados em condições subaéreas por processos físicos e químicos, resultando no aprofundamento das cavidades e origem dos tanques naturais durante o Pleistoceno Final. Posteriormente, as depressões foram preenchidas por sedimentos resultantes do intemperismo físico em áreas adjacentes e, ocasionalmente, por restos fósseis da megafauna pleistocênica, carreados pelo escoamento superficial. Apesar de atribuir um período de tempo curto para a formação de tanques naturais, é possível notar que, assim como no trabalho de Oliveira \& Hackspacher (1989), o controle estrutural a partir de rochas pré-cambrianas parece novamente ter sido levado em consideração para explicar a possível origem e distribuição das depressões.

As duas propostas elaboradas por Mabesoone et al. (1990) para a formação de uma depressão, seja por influência de fraturas e diáclases, ou pela distribuição de xenólitos decompostos, baseiam-se em um esquema estrutural pré-estabelecido para compreender a expansão ou aprofundamento dessas formas posteriormente. Segundo esses autores, os tanques aumentaram seu tamanho pelo processo de evorsão de águas pluviais torrenciais, típicas de clima semiárido que carrearam fragmentos de rochas, incluindo seixos, resultando em atrito sobre o embasamento cristalino. A intensidade e frequência desse processo de abrasão, além da ação química das águas estagnadas, produziriam tanques mais rasos, enquanto outros seriam mais aprofundados com paredes bastante íngremes. Geralmente, os fósseis são encontrados nos tanques mais profundos (Paula-Couto, 1980; Araújo-Júnior \& Porpino, 2011).

Os aspectos levantados em estudos anteriores para a geração dos tanques induzem à ideia de que as formas atualmente expostas nos maciços estão relacionadas à erosão diferencial associada ao sistema de fraturas, presença de corpos estranhos no embasamento (e.g. xenólitos) ou ao trabalho contínuo de rios sobre o leito rochoso. Entretanto, alguns autores têm associado formas análogas aos 
tanques nordestinos em outros continentes ao trabalho de corrosão química e/ou efeito de migração e concentração de cargas sobre o embasamento cristalino em subsuperfície (Twidale, 1989; Vidal Romaní, 1989; Campbell \& Twidale, 1995; Campbell, 1997; Vidal Romaní \& Twidale, 1998; Vidal Romaní \& Yepes Termiño, 2004; Twidale \& Vidal Romaní, 2005; Mayor Rodriguez, 2011).

\subsection{Importância dos tanques na preservação de fós- seis da megafauna pleistocênica}

A descoberta do conteúdo fossilífero preservado em tanques naturais é um marco na história do desenvolvimento da Paleontologia no Brasil. No ano de 1784, o então governador da capitania do Ceará, João Batista de Azevedo Coutinho de Montaury, foi responsável pelo envio de fósseis recolhidos de tanques naturais no vale do Rio Acaraú, município de Sobral, atual estado do Ceará, para o Reino de Portugal. Os fósseis em questão correspondem à primeira descoberta documentada, através de correspondências, da megafauna pleistocênica do país (Fernandes et al., 2013a). No início do século XIX, o padre português Manuel Aires de Casal faz um dos primeiros registros sobre a ocorrência de fósseis de animais "de antiguidade" encontrados em tanques no Nordeste do Brasil (Casal, 1817a, 1817b; Fernandes et al., 2013b). Já na clássica obra intitulada Reise in Brasilien (Viagem pelo Brasil, 1817-1820), escrita pelos naturalistas alemães Spix e Von Martius, há o registro de um dos primeiros resgates de fósseis da megafauna do Quaternário. Os restos fósseis, a "parte craniana" e "um fêmur de um mastodonte", foram encontrados e retirados de tanques próximos à Serra de Itauba e na localidade de Monte Santo, no interior da Bahia. Durante os séculos XIX e XX, inúmeras expedições organizadas pelo Museu Nacional partiam do Rio de Janeiro para o Nordeste do país com a finalidade de resgatar e transportar os fósseis para a antiga capital do império. No início do século passado, entre os pesquisadores estrangeiros que chegaram a observar a singularidade dos tanques, destaca-se John Casper Branner. 0 geólogo chegou a descrever a ocorrência de fósseis de mamíferos no interior de Pernambuco e de Alagoas (Branner, 1902).

A maior parte dos fósseis da megafauna pleistocênica coletada no Nordeste do Brasil tem sido recuperada de depósitos de tanque (Araújo-Júnior \& Porpino, 2011; Araújo-Júnior et al., 2013a), sendo os demais provenientes de uma ampla variedade de tipos de depósitos comuns na região, como por exemplo, cavernas, lagoas, olhos-d'água e vazantes (Bergqvist et al., 1997). Recentemente, Araújo-Júnior et al. (2013a) distinguiram os tanques naturais dos depósitos de tanque. Para esses autores, os tanques naturais consistem nas depressões produzidas pelo processo de intemperismo físico-químico em rochas do embasamento, enquanto que os depósitos de tanque compreendem o conteúdo sedimentar que preencheu essas depressões durante o Pleistoceno Final-Holoceno inicial. 0 estudo das acumulações fossilíferas desses depósitos configura-se como uma das principais ferramentas para o entendimento dos paleoambientes e de aspectos paleoecológicos da Região Intertropical Brasileira (RIB; sensu Cartelle, 1999) durante o Quaternário.

Depósitos de tanque consistem no tipo mais singular de depósito fossilífero da América do Sul. Compreendem pequenos corpos sedimentares de idade quaternária que preenchem os tanques naturais em rochas de embasamento no Nordeste do Brasil (Araújo-Júnior et al., 2013a). Esses depósitos são quase sempre estratificados e fossilíferos, preservando restos de uma diversificada fauna que inclui principalmente a megafauna do Pleistoceno Final-Holoceno inicial, como, por exemplo, megateriídeos, gliptodontídeos, gonfoteriídeos, toxodontídeos, macrauqueniídeos e felídeos (Paula-Couto, 1980; Mabesoone et al., 1990; Bergqvist et al., 1997; Cartelle, 1999). Em alguns casos, fósseis da megafauna estão associados a restos de pequenos mamíferos, anfíbios, crocodilos, quelônios, lagartos e aves (Paula-Couto, 1980; Dantas et al., 2005; Araújo-Júnior \& Moura, 2014; Araújo-Júnior et al., 2016). 0 quadro 1 apresenta uma listagem de todos os grupos de vertebrados até o momento identificados em depósitos de tanque no Nordeste do Brasil.

\section{3 Área, materiais e métodos}

O setor de estudo inclui parte da região do Nordeste do Brasil, mais precisamente os estados do Ceará, Rio Grande do Norte, Paraíba, Pernambuco, Alagoas, Sergipe e a parte norte do estado da Bahia (Fig. 1). A paisagem do interior do Nordeste é constituída por uma ampla variedade de cenários geomorfológicos. Existem amplos vales interioranos, serras escarpadas, extensas depressões sertanejas, maciços estruturais, superfícies de aplainamento e os inselbergs, ou pães-de-açúcar, os quais despontam na paisagem do nordeste brasileiro.

Geralmente os tanques naturais ocorrem próximos aos maciços rochosos, lajedos e, ocasionalmente, nos chamados mares de pedra ou blocos (campo de matacões), aflorando em meio à típica 
vegetação de caatinga.

Quadro 1. Diversidade de vertebrados identificados em depósitos de tanque do Nordeste do Brasil. * vertebrados com porte maior que $100 \mathrm{~kg}$; ${ }^{* *}$ vertebrados com porte entre $10 \mathrm{~kg}$ e $100 \mathrm{~kg}$; ${ }^{* *}$ vertebrados com porte menor que $10 \mathrm{~kg}$ (fonte: PaulaCouto, 1980; Bergqvist et al., 1997; Dantas et al., 2005; Silva, 2008; Oliveira et al., 2009; Araújo-Júnior \& Porpino, 2011, AraújoJúnior et al., 2013a, 2013b, 2015; Ribeiro, 2014; Silva, 2014).

Chart 1. Diversity of vertebrates identified in tank deposits in the Northeastern of Brazil. * vertebrates larger than $100 \mathrm{~kg}$; ** vertebrates weighing between $10 \mathrm{~kg}$ and $100 \mathrm{~kg}$; *** vertebrates smaller than $10 \mathrm{~kg}$ (source: Paula-Couto, 1980; Bergqvist et al., 1997; Dantas et al., 2005; Silva, 2008; Oliveira et al., 2009; Araújo-Júnior \& Porpino, 2011, Araújo-Júnior et al., 2013a, 2013b, 2015; Ribeiro, 2014; Silva, 2014).

\begin{tabular}{|c|c|c|}
\hline \multicolumn{2}{|c|}{ Mamíferos } & Répteis \\
\hline \multirow{19}{*}{$\begin{array}{l}\text { Xenarthra - Pilosa } \\
\text { Eremotherium* } \\
\text { Glossotherium* } \\
\text { Catonyx* } \\
\text { Ocnotherium* } \\
\text { Nothrotherium** } \\
\text { Xenarthra-Cingulata } \\
\text { Glyptotherium* } \\
\text { Panochthus* } \\
\text { Glyptodon* } \\
\text { Hoplophorus* } \\
\text { Neuryurus* } \\
\text { Pampatherium* } \\
\text { Holmesina* } \\
\text { Dasypus*** } \\
\text { Euphractus*** } \\
\text { Tolypeutes*** } \\
\text { Pachyarmatherium** } \\
\text { Litopterna } \\
\text { Xenorhinotherium* } \\
\end{array}$} & \multirow{19}{*}{$\begin{array}{l}\text { Proboscidea } \\
\text { Notiomastodon* } \\
\text { Notoungulata } \\
\text { Toxodon* } \\
\text { Perissodactyla } \\
\text { Equus* } \\
\text { Hippidion* } \\
\text { Tayassu** } \\
\text { Artiodactyla } \\
\text { Palaeolama* } \\
\text { Mazama** } \\
\text { Ozotocerus }{ }^{* *} \\
\text { Blastocerus** } \\
\text { Carnivora } \\
\text { Smilodon* } \\
\text { Panthera** } \\
\text { Leopardus*** } \\
\text { Protocyon ** } \\
\text { Cerdocyon } \\
\text { *** }\end{array}$} & Testudines \\
\hline & & Geochelone *** $^{* *}$ \\
\hline & & Crocodylia \\
\hline & & Caimaninae indet.** \\
\hline & & Ophidia \\
\hline & & Ophidia indet.*** \\
\hline & & Lacertilia \\
\hline & & Lacertilia indet.*** \\
\hline & & Aves \\
\hline & & Rheiformes \\
\hline & & Rhea?** \\
\hline & & Acciptriformes \\
\hline & & Acciptriformes indet.*** \\
\hline & & Anfíbios \\
\hline & & Anura \\
\hline & & Rhinella*** \\
\hline & & \\
\hline & & \\
\hline & & \\
\hline
\end{tabular}

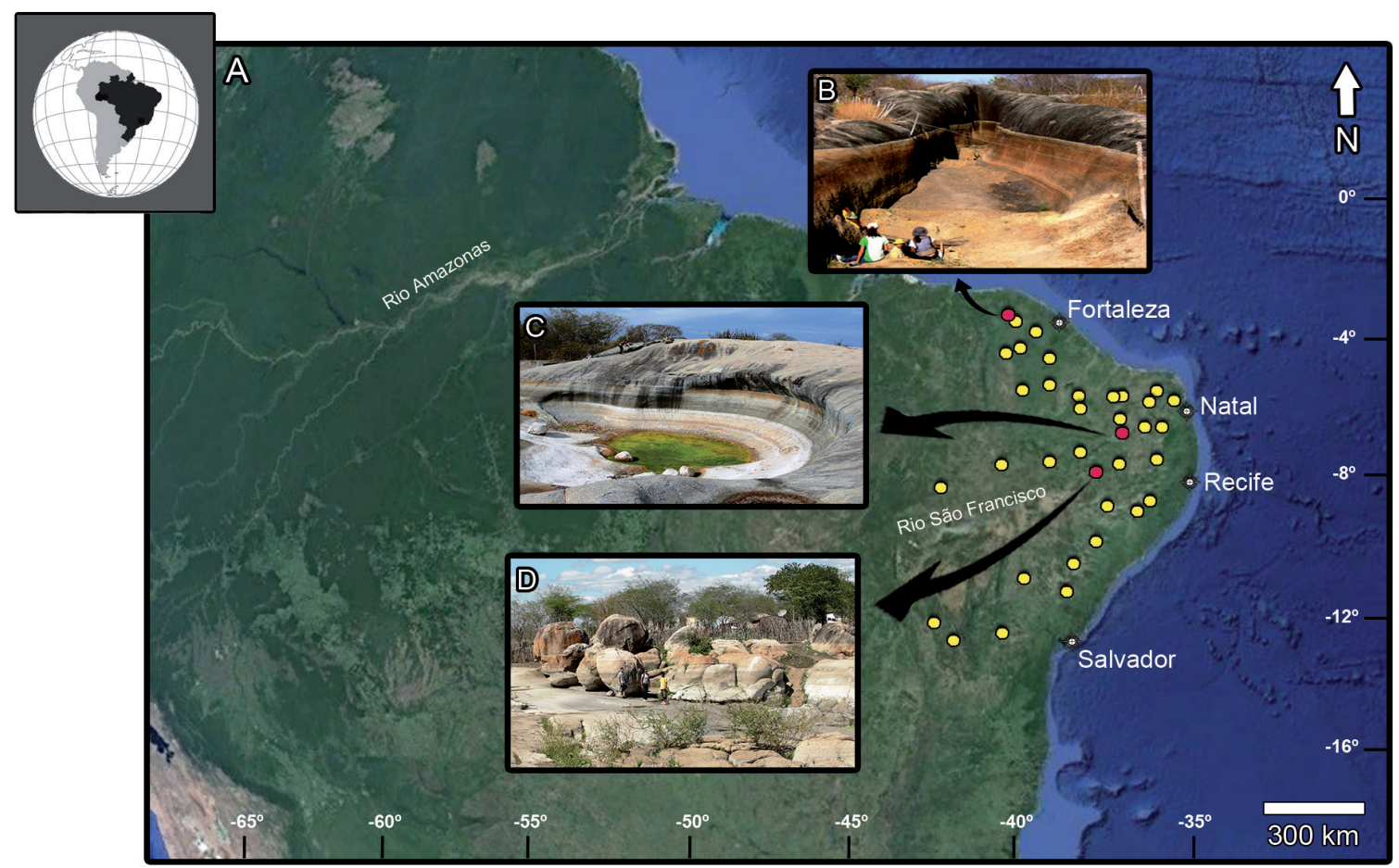

Figura 1. Mapa de ocorrência de tanques (lato sensu) fossilíferos estudados na região nordeste do Brasil. A) Os pontos amarelos representam depósitos de tanques avaliados em trabalhos prévios sobre termos taxonômicos, tafonômicos ou paleoecológicos; os pontos vermelhos são tanques representados em B-D; B) Tanque de Jirau, no Sítio Paleontológico de Jirau, Itapipoca, Ceará; C) Tanque no Sítio Paleontológico de Curimatãs, Pocinhos, Paraíba; D) Tanque no Sítio Paleontológico de Lage Grande, Alagoinha, Pernambuco. Escalas em B-D: Escala humana. Fonte do mapa: Google Earth (modificado de Araújo-Júnior, 2016).

Figure 1. Map of the occurrence of fossiliferous tanks (lato sensu) studied in the Northeastern of Brazil. A) The yellow dots represent tank deposits evaluated in previous works on taxonomy, taphonomy or paleocology terms; red dots are tanks represented in B-D; B) Tank of Jirau, at Jirau Paleontological Site, Itapipoca, state of Ceará; C) Tank at Curimatãs Paleontological Site, Pocinhos, state of Paraíba; D) Tank at Lage Grande Paleontological Site, Alagoinha, state of Pernambuco. Scale in B-D: human scale. Source of map: Google Earth (modified from Araújo-Júnior, 2016). 
O arcabouço geológico da área de estudo ocupa por completo a Província Borborema e a parte setentrional do Cráton do São Francisco (Fig. 2). Segundo Almeida et al. (1981) a Província Borborema compreende uma área do Nordeste setentrional localizada a leste da Bacia do Parnaíba e ao norte do Cráton do São Francisco. Rodrigues et al. (2010) definem a Província como uma ampla região brasiliana constituída por litologias metamórficas e ígneas, formada por um sistema ramificado de orógenos neoproterozoicos, separados por terrenos de idade proterozoica que, eventualmente, apresentam núcleos arqueanos (Almeida et al., 1981; Brito Neves et al., 2000). Os autores ainda destacam a complexidade estratigráfica e geocronológica da área que define uma série de compartimentos tectônicos caracterizados por diferentes aspectos geológicos e geofísicos (Rodrigues et al., 2010). Já o Cráton do São Francisco é constituído por um bloco arqueano que ficou poupado das orogêneses do Proterozoico e partes de um orógeno paleoproterozoico, desenvolvido durante o evento Transamazônico, por volta de 2,1 Ga (Alkmim, 2004). Segundo Teixeira et al. (2000), o embasamento cristalino do Cráton do São Francisco é formado por uma complexa disposição de terrenos de alto grau metamórfico, constituído por gnaisses, granitoides e granulitos de idade arqueana, conjuntos do tipo granito greenstone e faixas móveis de rochas supracrustais paleoproterozoicas. Na parte nordeste do Cráton do São Francisco encontram-se rochas de origem plutônica aflorantes e caracterizadas pela elevada variedade composicional.

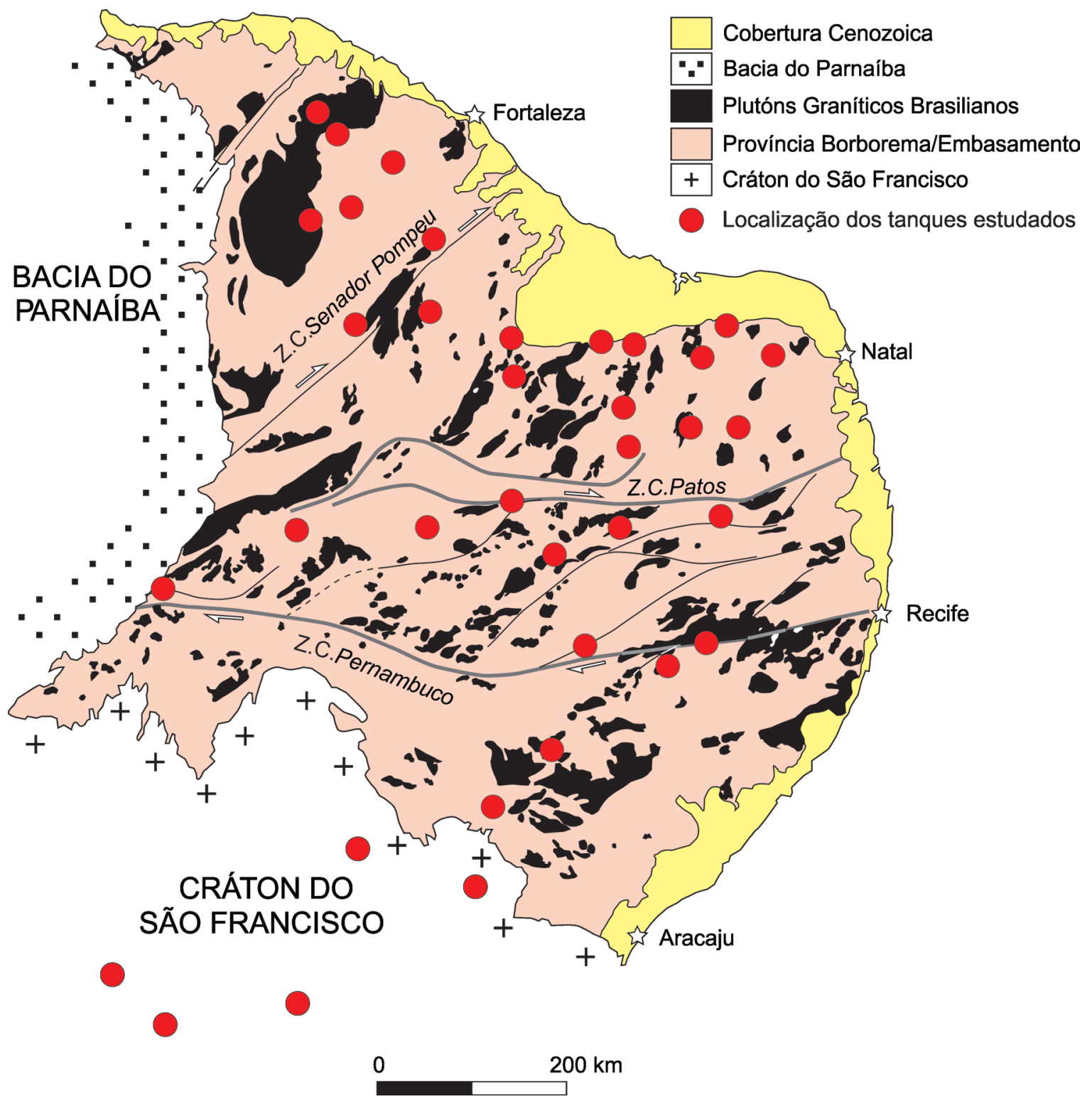

Figura 2. Província Borborema (Nordeste do Brasil) destacando a localização de tanques (lato sensu) fossilíferos estudados, as rochas plutônicas do Brasiliano-Pan Africano e as zonas de cisalhamento (modificado de Archanjo et al., 2008).

Figure 2. Borborema Province (Northeastern Brazil) highlighting the location of fossiliferous tanks (lato sensu) studied, the Brasiliano-Pan African plutonic rocks and shear zones (modified from Archanjo et al., 2008). 
Destaca-se na Província Borborema um amplo magmatismo associado ao evento orogênico brasiliano, entre 750 e $540 \mathrm{Ma}$, durante o Neoproterozoico, com extensos e diversificados plútons graníticos nos quais ocorre a maior parte das formas minoritárias do relevo existentes na paisagem sertaneja. Entre as inúmeras formas destacam-se os tanques naturais de variados tamanhos e cotas altimétricas sobre o embasamento cristalino.

0 presente trabalho elaborou um minucioso levantamento bibliográfico sobre a utilização do termo "tanque", a importância paleontológica dessas cavidades no Nordeste do Brasil e as diversas interpretações para a possível origem dos tanques naturais, incluindo estudos de formas análogas em outros continentes. Foram consultados trabalhos acadêmicos elaborados desde o início do século XIX até artigos mais recentes, incluindo dissertações e teses. Informações mais antigas, como menções constantes na correspondência ultramarina entre o Brasil Colônia e a Metrópole (Reino de Portugal), durante o século XVIII, foram consultadas no trabalho de Fernandes et al. (2013a).

A maior parte da compilação de materiais acadêmicos sobre a gênese dos tanques data desde o final do século XIX até meados dos anos de 1990. Os trabalhos mais recentes, dos anos 2000 até hoje, baseiam-se em estudos de feições similares aos tanques naturais do nordeste brasileiro observadas em diferentes países da Europa e Oceania. 0 conjunto de observações e análises elaboradas em numerosos trabalhos de campo realizados por alguns dos autores deste trabalho em sítios paleontológicos na região Nordeste do Brasil, adicionado à revisão da literatura sobre o assunto, auxiliaram na proposta de sequência evolutiva de hipóteses e modelos sobre a origem dos tanques naturais nordestinos.

A classificação morfométrica e os tipos genéticos foram utilizados com base nas características definidas por Mayor Rodriguez (2011) para feições análogas aos tanques encontradas no noroeste da Espanha, a saber: o comprimento, largura, profundidade e presença, ou não, de exutório na área da cavidade. Também seguindo este autor, foi utilizada uma classificação genética em: monofásicos ou polifásicos (ver item 4.3). Já a morfologia dos tipos de fundo foi baseada em Twidale \& Vidal Romaní (2005). 0 trabalho apresenta as diferentes morfologias que se desenvolvem e caracterizam o fundo da cavidade, sendo côncavo, plano ou em forma de poltrona. 0 quadro comparativo entre a denominação e características de tanques naturais e caldeirões foi preparado com base na classificação de Pedraza (1996). 0 quadro tende a expor a diferen- ciação e especificidades (características) entre as formas associadas à gênese fluvial e não-fluvial. Em suma, a compilação de estudos e levantamentos de trabalhos anteriores de feições análogas em outros continentes, auxiliou a elaborar uma classificação dos tanques naturais do Nordeste, levando em consideração sua origem e desenvolvimento.

\section{Resultados e discussão}

\subsection{Levantamento de terminologias}

As primeiras referências sobre os tanques (lato sensu) na literatura brasileira datam do final do século XVIII e início do século XIX, na abertura das depressões para construção de reservatórios de água nas épocas das secas e, consequentemente, durante a escavação, a descoberta do conteúdo fossilífero de mamíferos quaternários (Casal, 1817a, 1817b; Spix \& Martius, 1824; Burlamaque, 1855, 1856; Hartt, 1870; Branner, 1902, 1915; ver também Fernandes et al., 2012, 2013a, 2013b e referências incluídas). Entretanto, estas estruturas têm sido notadas e discutidas ao longo de vários séculos. No Brasil os tanques já foram denominados como cacimbas, caldeirões, oriçangas, panelas, potes, buracos ou depressões de intemperismo.

Entre os anos de 1848 e 1862, o Museu Nacional empreendeu e organizou várias expedições científicas ao Nordeste do país (Fernandes et al., 2010). 0 resultado dessa iniciativa foi o resgate de uma quantidade considerável e variada de fósseis da Megafauna brasileira. Em 1855, o coordenador-chefe do Museu Nacional, Frederico Burlamaque, recebeu o total de 85 caixões, uma das remessas mais volumosas, com ossos fósseis recuperados provenientes de povoado chamado Tanque da Aldeia e regiões circunvizinhas de Alagoas (Fernandes et al., 2010, 2012). Em 1853, outra remessa foi enviada a partir da localidade chamada Caldeirão, município de Santa Brígida, Bahia. Entretanto, o abundante material associado ao conteúdo fossilífero não consta no recebimento oficial do Museu Nacional (Fernandes et al., 2010, 2012). Outras áreas fontes de materiais fossilíferos, resgatados de tanques naturais durante o mesmo período de tempo, foram: Tanque Velho e Tanque dos Elefantes, município de Pão de Açúcar, em Alagoas, e o povoado de Tanque Velho, em Sítios Novos, município de Canhoba, em Sergipe (Fernandes et al., 2012). Pode ser levantada a hipótese de que a generalização do termo tanque (e caldeirão) esteja também associada aos nomes das localidades, onde os primeiros fósseis foram recuperados no Brasil. 
De acordo com Oliveira (1989) o termo tanque foi empregado pela primeira vez por Luciano Jacques de Moraes em 1924, no trabalho intitulado Serras e Montanhas do Nordeste. Entretanto, trabalhos mais antigos, como do Pe. Aires de Casal, em 1817, já utilizavam o termo tanque associado às pequenas depressões (Casal, 1817a, 1817b; Fernandes et al., 2013b). Nas obras de Spix e Martius, em 1824, de C. F. Hartt, em 1870, e de J. C. Branner, em 1902, sobre a ocorrência de fósseis de mamíferos no interior da Bahia, de Pernambuco e de Alagoas, nomeavam as cavidades escavadas no embasamento cristalino como tanks (em português, tanques). Originalmente escrito em língua germânica, Spix e Martius mantiveram os termos tanques e caldeirões no texto (Spix \& Martius, 1828, 1968), enquanto que nos trabalhos em língua inglesa (Hartt, 1870; Branner, 1902) foram utilizados os termos tanks, cauldrons, pot-holes e rock basins. Posteriormente, os trabalhos escritos em língua inglesa foram traduzidos, sendo mantidos os termos tanques e caldeirões, e publicados, respectivamente, em 1941 pela Editora Nacional e em 1948 no periódico Boletim Geográfico (Hartt, 1941; Branner, 1948).

Em diversas partes do mundo feições semelhantes aos tanques (lato sensu) são chamados por uma ampla variedade de nomes e entre as menores formas que constituem o relevo, talvez, sejam as mais conhecidas (Campbell \& Twidale, 1995). Segundo o trabalho de Vidal Romaní \& Twidale (1998) - no limite do conhecimento alcançado - elas foram descritas pela primeira vez em 1291 na cidade de Dartmoor, Sudoeste da Inglaterra. As formas foram denominadas como Rock Basins ou Rock Basons.

A despeito da classificação morfológica, diversos termos têm sido verificados na literatura em língua inglesa, a exemplo de Rock Basins, Rock Holes, Weather Pits, Water Eyes, Pot Holes, Cauldrons ou Granite Pits. 0 termo Gnamma, de origem aborígene da Austrália, traduzido ao português como "buraco de água", tem sido aceito e utilizado internacionalmente (Bigarella, 1994; Twidale \& Campbell, 2005). Na Espanha são chamados Pílas, Hoyos, Caçolas e Pilancones, na região da Galícia são denominados de Pias, e na Catalunha de Cadolles ou Cassoletes. De acordo com Vidal Romaní \& Twidale (1998) na literatura francesa são chamados Tanques e Vasques Rocheuses; na língua germânica são denominados de Verwitterrungsnäpfe, Opferkessel, Baumverfallspingen, Felsschüssel e Dellen; e em polonês, de Kociolli.

\subsection{Morfologia geral dos tanques}

Os tanques naturais (stricto sensu) são depressões produzidas no embasamento cristalino, geralmente constituído por substrato ígneo ou metamórfico (Paula-Couto, 1980; Oliveira \& Hackspacher, 1989; Santos et al., 2002; Araújo-Júnior \& Porpino, 2011). No entanto, podem ocorrer também em rochas sedimentares, de forma ocasional (Mabesoone et al., 1990). No nordeste brasileiro, a maioria é constituída por formas ovaladas, elípticas e/ou circulares (Ximenes, 2009). Alguns tanques naturais possuem contornos angulares, indicando a influência de fraturas e descontinuidades no entorno de maciços; outros possuem as feições internas suavizadas pelo trabalho contínuo da frente intempérica, definindo antigas zonas umedecidas de contato solo-rocha. Em feições análogas encontradas fora do Brasil, existem ainda os casos onde as depressões são resultantes da coalescência de duas ou mais cavidades criando formas lobuladas no terreno granítico (Vidal Romaní \& Twidale, 1998; Twidale \& Vidal Romaní, 2005).

Os tanques se distinguem na paisagem sertaneja por sua capacidade de retenção do escoamento superficial (Ximenes, 2003, 2009). Em casos de precipitações torrenciais, típicas do semiárido, a água é evacuada da concavidade pelo processo de transbordamento difuso em toda parte do contorno do tanque, ou através de um canal preferencial denominado exutório. No entanto, segundo Vidal Romaní \& Twidale (1998) é mais comum que a água desapareça das concavidades por meio da evaporação.

\subsubsection{Classificação morfométrica dos tanques}

Utilizando alguns parâmetros para a classificação de cavidades elaborada por Mayor Rodriguez (2011), no maciço granítico de 0 Pindo, Noroeste da Espanha, as variáveis morfométricas que definem as cavidades são: o comprimento (C), a largura (L), a profundidade (P), e, em alguns casos, a altura do exutório (E). Se considerarmos o parâmetro $\mathrm{P}$, o mais relevante por ser o indicativo de desenvolvimento do tanque natural, a seguinte situação pode ser apresentada:

- Se $\mathrm{P}=0$, a forma ainda está por iniciar;

- Se $\mathrm{P} / \mathrm{E}=1$, a forma não apresenta ainda exutório desenvolvido e corresponderia a um tanque em estágio embrionário;

- Se a relação $\mathrm{P} / \mathrm{E}$ é > 1, o tanque está em estágio evolutivo.

Considerando somente os parâmetros C e L, obtém-se a forma em planta do tanque. Assim: 
- Se C = L, a morfologia é circular;

- Se C > L, a morfologia é elíptica ou ovalada.

Em alguns casos o controle exercido pela presença e distribuição de fraturas e/ou juntas no substrato rochoso pode resultar, sobre a morfologia do tanque, em formas angulares em planta. 0 contato entre a base do material regolítico com as zonas de debilidade do embasamento cristalino, como as diáclases, pode permanecer estável por um longo período de tempo. Assim, as formas angulares podem ser reafeiçoadas pelo trabalho contínuo da frente intempérica em subsuperfície, mascarando as feições lineares típicas de fraturas.

A distribuição de formas semelhantes, como as depressões na superfície rochosa, em contextos diferenciados da paisagem nordestina levou ao uso indiscriminado do termo tanque (lato sensu). Segundo a classificação básica de Pedraza (1996) é possível esclarecer, levando em consideração os parâmetros (L, C e P), as morfologias de cavidades em detalhe, produzidas por diferentes processos. No caso, os tanques, não fluviais, e os caldeirões ou marmitas, de origem fluvial (Quadro 2).

Quadro 2. Principais características e origem das formas de tanques naturais e caldeirões/marmitas (modificado de Pedraza, 1996).

Chart 2. Main characteristics and origin of the forms of natural tanks and the cauldrons/cylindrical basin (modified from Pedraza, 1996).

\begin{tabular}{|c|c|c|c|}
\hline \multicolumn{2}{|c|}{ Denominação } & Características & Gênese \\
\hline \multirow{2}{*}{$\begin{array}{l}\text { Tanques } \\
\text { naturais } \\
\text { (formas não- } \\
\text { fluviais) }\end{array}$} & $\begin{array}{l}\text { Tanques } \\
\text { rasos }\end{array}$ & $\begin{array}{l}\text { São depressões naturais produzidas em } \\
\text { superfícies horizontais e/ou subhorizontais do } \\
\text { substrato rochoso cristalino. Na maior parte das } \\
\text { vezes são pouco profundos e com caráter esférico } \\
\text { e/ou elipsoidal,raramente cônicos. Em geral } C>\mathrm{L} \text {, } \\
\text { podendo ser } C \sim \mathrm{L} \text {, mas sempre } \mathrm{P}<\mathrm{C} \text { ou L (Fig. } 3 \mathrm{~A} \text { ). }\end{array}$ & $\begin{array}{l}\text { Sua origem } r \text { está } \\
\text { relacionada a condições } \\
\text { subedáficas e ao } \\
\text { processo de migração e } \\
\text { concentração de cargas } \\
\text { (ver detalhes no item } \\
4.3 .2 \text { ). }\end{array}$ \\
\hline & $\begin{array}{c}\text { Tanques } \\
\text { escarpados }\end{array}$ & $\begin{array}{l}\text { São depressões naturais produzidas em } \\
\text { superfíciesinclinadas,verticaise/ousubverticais, } \\
\text { do substrato rochoso cristalino. Geralmente } \\
\text { apresentam formas ocas e estreitas, balizadas } \\
\text { por paredes íngremes. Aparentemente são } \\
\text { fundos e com caráter elipsoidal e/ou alongado. } \\
\text { Em geral C > L, mas sempre P > L (Fig. 3B). }\end{array}$ & 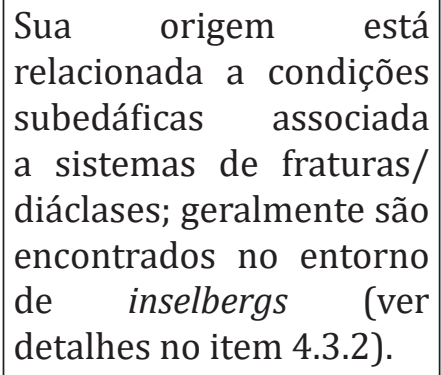 \\
\hline \multicolumn{2}{|c|}{$\begin{array}{l}\text { Caldeirões ou marmitas } \\
\text { (formas fluviais) }\end{array}$} & $\begin{array}{l}\text { A morfologia tende a ser cônica ou cilíndrica e } \\
\text { apresentam maior profundidade que as formas } \\
\text { não-fluviais. Emgeral, } \sim \sim \mathrm{L} \sim \text { Pou } P>C \sim \mathrm{L} \text { (Fig. } 3 \mathrm{C} \text { ). }\end{array}$ & $\begin{array}{l}\text { Originados somente em } \\
\text { condições subaéreas e } \\
\text { são sempre associados } \\
\text { ao trabalho de evorsão } \\
\text { em leitos de rios. }\end{array}$ \\
\hline
\end{tabular}

Comumente os tanques naturais têm sido confundidos com caldeirões, porém, embora ambos sejam depressões produzidas em substrato cristalino, diferem em termos de processo genético (Fig. 3). No nordeste brasileiro, os caldeirões, ou marmitas, consistem em perfurações cilíndricas, com forma variada em planta, ainda que geralmente sejam circulares com uma seção transversal retangular. Em língua inglesa, os cylindrical basin (= marmitas) são denominadas apropriadamente como formas cilíndricas ou em bainha (Mayor Rodrigues, 2011). As marcas nas paredes do cilindro, semelhantes a golpes contínuos de goiva, sugerem o efeito turbulento do escoamento superficial concentrado durante períodos de chuvas torrenciais
(Vidal Romaní \& Twidale, 1998). Normalmente essas feições encontram-se preenchidas por detritos ou recobertas por vegetação arbustiva.

Na paisagem os tanques variam em forma e tamanho. 0 diâmetro médio dos tanques observados na Europa é da ordem de $1 \mathrm{~m}$ e profundidade média em torno de 0,5 m (Vidal Romaní \& Twidale, 1998); entretanto a maioria dos tanques brasileiros apresenta dimensões maiores. De acordo com Ximenes (2009), na localidade de Itapipoca, Ceará, por exemplo, os maiores tanques possuem dimensões que variam entre 10 a $20 \mathrm{~m}$ de comprimento, 5 a $8 \mathrm{~m}$ de largura, e profundidade de até $10 \mathrm{~m}$ (Fig. 4). 

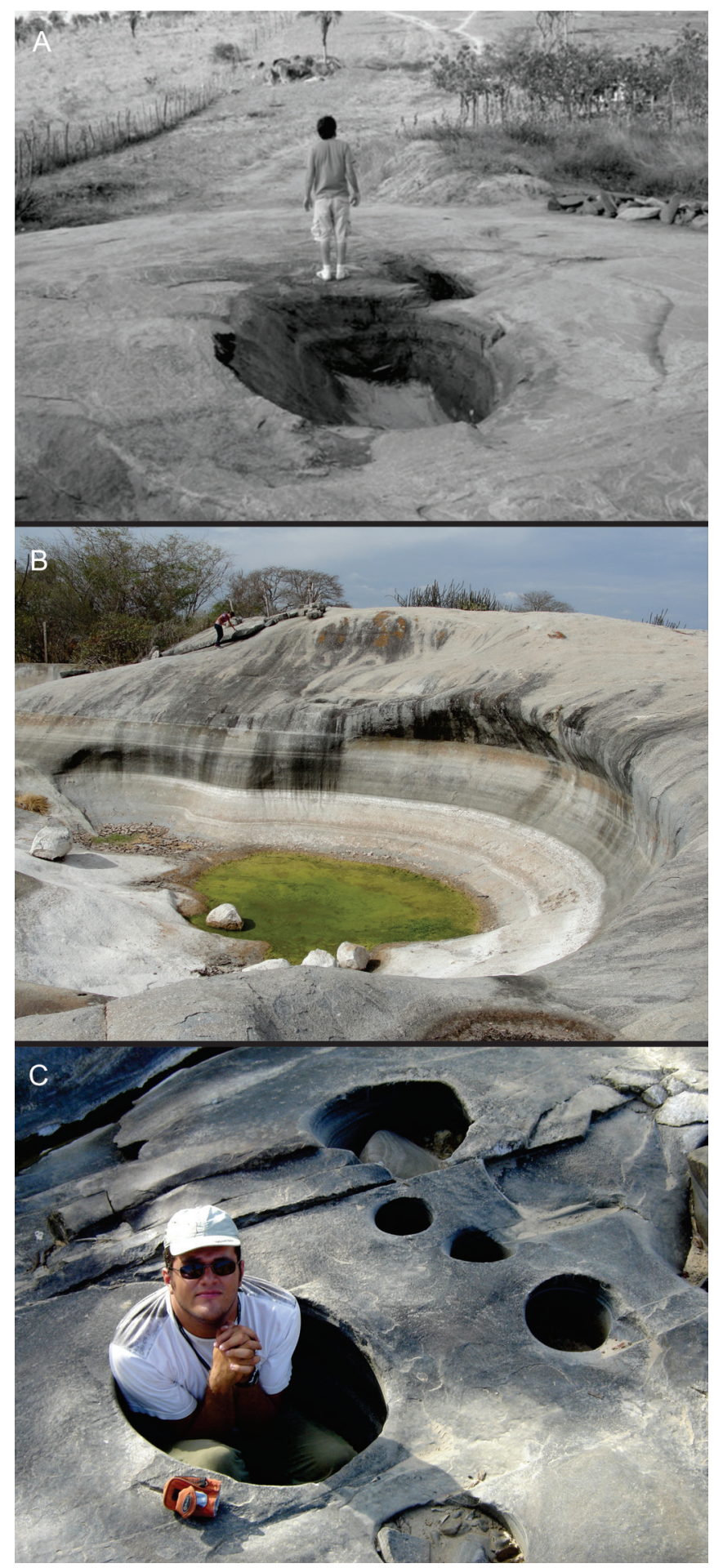

Figura 3. Os diferentes aspectos morfométricos. A) Tanque natural raso de pequeno porte encontrado em superfície subhorizontal na localidade de Lagoa do Rumo, município de Baixa Grande, Bahia (retirado de Faria et al., 2013); B) Tanque natural escarpado com a presença de exutório, encontrado na borda de um domo granítico na localidade de Curimatãs, município de Pocinhos, Paraíba; nota-se a coalescência de cavidades dando um aspecto lobulado ao tanque; C) Marmita (ou caldeirão) com aspecto cilíndrico e profundidade maior que a área da feição estabelecida, localidade próxima a Ingá, Paraíba. Algumas cavidades encontram-se entulhadas com material sedimentar detrítico.

Figure 3. The different morphometric aspects. A) Small-sized shallow tank found on subhorizontal surface in the locality of Lagoa do Rumo, municipality of Baixa Grande, Bahia (from Faria et al., 2013); B) Steeped tank with concave bottom found on the edge of a small granite dome in the locality of Curimatãs, municipality of Pocinhos, Paraíba; note the coalescence of cavities giving a lobed appearance to the tank; C) Cylindrical basin or Cauldron with cylindrical aspect and depth greater than the area from the feature established, locality near Ingá, Paraíba; some wells are filled with detrital sediment.

Ocasionalmente, os tanques naturais apresentam em seu perfil interno a forma de rampas ou patamares suaves que definem um aspecto escalonado na cavidade. Nas áreas mais elevadas da feição os tanques tendem a apresentar topos de geometria convexa seguido de suaves rampas, 
ou mesmo reentrâncias de superfícies íngremes, que seguem até a parte inferior. Segundo Twidale (1968) essas características de reentrâncias, denominados flared slopes (na língua inglesa) ou zapatas (no espanhol), e de patamares bem definidos no perfil sinalizam a ideia de que as formas em questão estão associadas ao trabalho contínuo da frente de intemperismo em subsuperfície e da ex- posição episódica (Figs. 3B e 5). As zonas de recuo do perfil no afloramento rochoso delimitam as antigas superfícies de contato solo-rocha do tanque natural, já a exposição episódica está associada aos processos de remoção do material regolítico sobre a rocha. Geralmente a remoção do material sobrejacente está associada ao rebaixamento do nível de base local ou ao soerguimento regional.

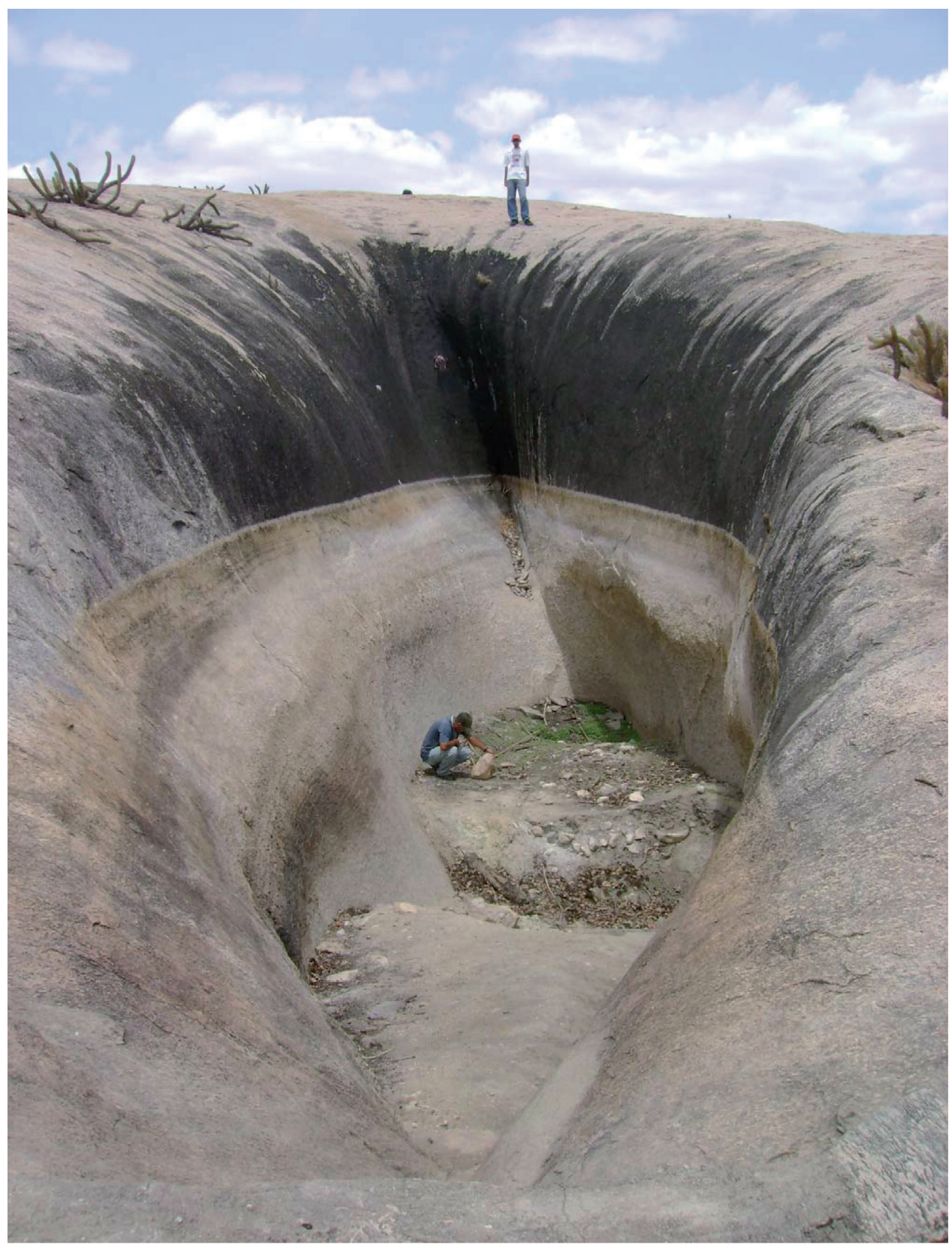

Figura 4. Tanque natural escarpado de grande profundidade localizado no município de Itapipoca, Ceará. Nota-se a presença do exutório que define um aspecto de poltrona ao tanque.

Figure 4. Deep steeped natural tank located in the municipality of Itapipoca, Ceará. Note the presence of the outlet that defines an armchair aspect to the tank. 


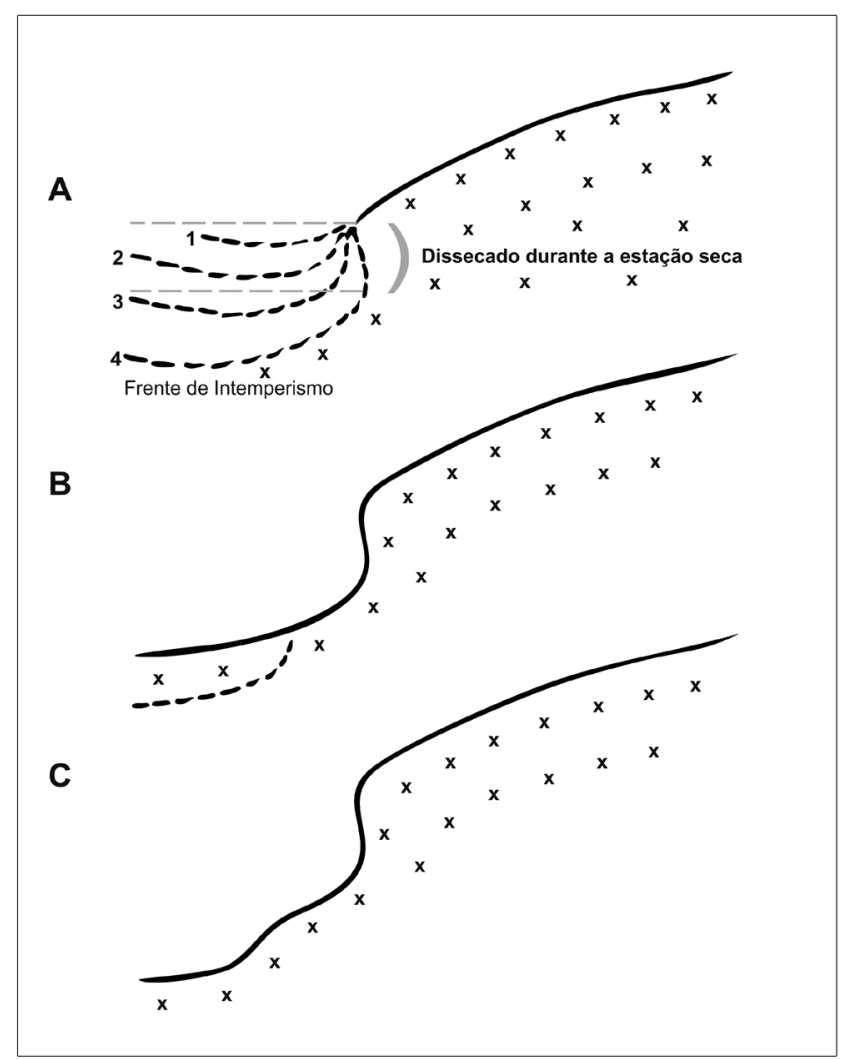

Figura 5. Evolução do flared slope por intemperismo na base da escarpa e erosão subsequente. A) Intemperismo intenso resultante do runoff na margem inferior da vertente; o número de linhas, 1 ao 4, representa os estágios do avanço da frente de intemperismo; B) Rebaixamento do nível de base, erosão de detritos alterados e exposição da frente intempérica como flared slope ou zapata; é possível observar a nova linha da frente intempérica e abaixo o novo plano de superfície; C) Desenvolvimento do duplo flared slope pela repetição do processo de duplo estágio (modificado de Twidale, 1968).

Figure 5. Evolution of flared slop by scarp foot weathering and subsequent erosion. A) Strong weathering by water derived from runoff at the lower margin of slope; numbered lines, 1 to 4, represent stages in advance of weathering front; B) Lowering of base level, erosion of weathered debris, and exposure of weathering front as a flared slope or zapata, with further weathering beneath the new plain surface; C) Development of double flare by repetition of the two-stage process (modified from Twidale, 1968).

\subsubsection{Classificação morfológica de fundo dos tan- ques}

Tomando como base a classificação de Twidale \& Vidal Romaní (2005) sobre as formas menores desenvolvidas em superfícies rochosas do embasamento cristalino, os tanques do nordeste brasileiro variam entre tanques de fundo côncavo, tanques de fundo plano e tanques em poltrona (Fig. 6): i) tanques de fundo côncavo são de seção hemisférica e se desenvolvem sobre superfícies suavemente inclinadas. Em muitos casos não possuem exutório definido, quando existe geralmente é estreito; ii) tanques de fundo plano são, em comparação com o anterior, menos profundos e têm fundo plano. Normalmente não possuem exutório definido e o transbordamento da água se produz ao longo de todo o contorno da concavidade. Em alguns casos esses tipos de tanques estão unidos por canais ou aberturas, formando parte de uma incipiente rede de drenagem; iii) tanques em poltrona possuem uma seção transversal assimétrica à linha de máxima pendente. Na parte superior, as paredes do tanque têm maior altura que na inferior, onde se localiza o exutório. Normalmente a área de escape prossegue como uma acanaladura ou mesmo uma estria. Estas formas são típicas de superfícies moderadamente inclinadas $\left(20^{\circ}-30^{\circ}\right)$ que seguem descendo desde as zonas planas da cimeira até as paredes inclinadas e áreas de planície nas adjacências.

\subsection{Origem dos tanques}

Segundo Mayor Rodriguez (2011), os modelos elaborados para a origem de feições análogas aos tanques naturais podem ser analisados em dois grupos distintos, os modelos monofásicos e os polifásicos (Quadro 3). 0 primeiro propõe uma origem estritamente subaérea para as cavidades. 0 modelo polifásico, por sua vez, propõe uma origem em subsuperfície para essas feições, podendo ser subedáficos ou gerados por concentração de cargas; posteriormente, essas depressões subsuperficialmente iniciadas são condicionadas aos mesmos controles exógenos indicados abaixo para os tanques de origem monofásica. 


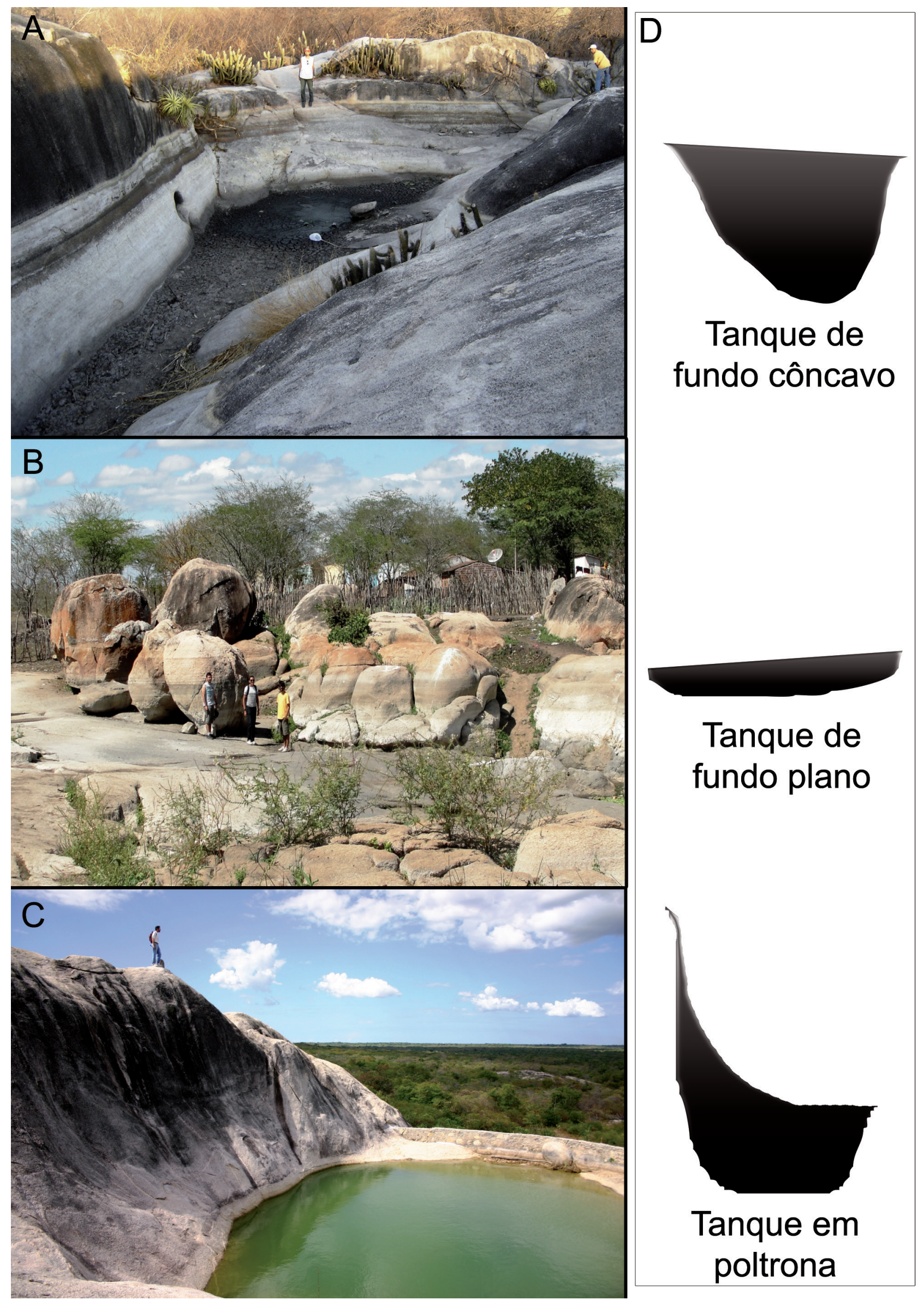

Figura 6. Morfologia de fundo. A) Tanque de fundo côncavo; B) Tanque de fundo plano; C) Tanque em poltrona; D) Perfil dos tanques em paralelo.

Figure 6. Bottom morphology. A) Concave bottom tank; B) Flat bottom tank; C) Arm-chair tank; D) Profile of tanks in parallel. 
Quadro 3. Tipos genéticos de gnammas (sensu Mayor Rodriguez, 2011), os quais podem ser aplicados aos tanques naturais do nordeste brasileiro (modificado de Mayor Rodriguez, 2011).

Chart 3. Genetic types of gnammas (sensu Mayor Rodriguez, 2011), which can be applied to the natural tanks in northeastern Brazil (modified from Mayor Rodriguez, 2011).

\begin{tabular}{|c|c|c|}
\hline Monofásicos & Polífásicos \\
\hline Controle estrutural & Subedáficos \\
\hdashline Controle litológico & & Via gravitacional \\
\hdashline Controle climático & Concentração de cargas & Via tectônica \\
\hdashline Controle biológico & & \\
\hdashline Controle dinâmico & & \\
\hline
\end{tabular}

\subsubsection{Tanques de origem monofásica}

Os tanques monofásicos possuem origem subaérea ou epigênico; são desenvolvidos pelo contato direto da água sobre a superfície rochosa, permanecendo estagnado em uma depressão preexistente. As feições expostas estariam associadas ao conjunto de fraturas expostas ou à distribuição de xenólitos no embasamento cristalino que são retrabalhados, de maneira contínua, pelo intemperismo físico, químico e/ou biológico.

De acordo com Mayor Rodriguez (2011) as cavidades, geralmente, possuem pequeno tamanho (centimétricos) de forma circular, não apresentam exutórios e ocorrem em grupos. 0 mesmo autor define os fatores que condicionam a origem de tanques monofásicos, entre eles os controles estrutural, litológico, climático, biológico e dinâmico: i) controle estrutural: os planos de foliação, sistema de diáclases ou nos pontos de interseção de fraturas; ii) controle litológico: os enclaves na superfície rochosa (e.g. xenólitos); iii) controle climático: processo de haloclastia, concentração de sais, ou mesmo pela umidade como fator predominante; iv) controle biológico: denominado como micro- pitting, são cavidades elaboradas por microfauna e flora; os líquens possuem papel predominante; v) controle dinâmico: as cavidades resultantes do processo de transporte e atrito de clastos carreados ao longo do leito fluvial (efeito de evorsão). 0 trabalho eólico também é considerado como agente dinâmico.

Os modelos anteriormente propostos para a origem de tanques naturais no nordeste brasileiro (Branner, 1915; Moraes, 1924; Moraes Rêgo, 1926; Domingues, 1952; Paula-Couto, 1953; Rolim, 1974, 1982; Mabesoone \& Castro, 1975; Santos, 1982; Oliveira, 1989; Oliveira \& Hackspacher, 1989; Oliveira et al., 1989; Mabesoone et al., 1990) baseiam-se fundamentalmente em três situações monofásicas: i) Processo de evorsão: o efeito seria o responsável pela corrosão sobre as rochas de leito do rio, sendo provocada por movimentos turbilhonares. Segundo alguns autores a abrasão física contínua, realizada por sedimentos arenosos e mobilizada por vórtices de água, resultaria em depressões conhecidas como marmitas, de formas cilíndricas; ii) Fator composicional do embasamento cristalino. A ideia de homogeneidade atribuída aos granitos pode levar o pesquisador a uma interpretação equivocada e parcial dos processos de formação dos tanques. A presença de xenólitos, ricos em biotita ou xenólitos melanocráticos de composição básica, pode induzir, por intemperismo diferencial, a formação de pequenas concavidades arredondadas. Esses pequenos enclaves podem, posteriormente, se desenvolver até formar depressões equivalentes a tanques com fundo côncavo e de grandes dimensões; iii) Influência do sistema de fraturas e diáclases: no nordeste brasileiro as regiões no entorno de inselbergs são áreas caracterizadas pelo intenso fraturamento e a presença de grandes descontinuidades. As zonas em questão estão associadas também à concentração da maior parte dos tanques fossilíferos já encontrados na paisagem da depressão sertaneja. Em trabalhos anteriores a gênese desses tanques foi associada ao trabalho intempérico que percorre as linhas ou zonas de maior suscetibilidade ou fraqueza do terreno, no caso, o sistema de fraturas e diáclases.

Em todos os modelos apresentados a água, envolvida nos processos de solução, hidratação e hidrólise, é a responsável pela meteorização diferencial na frente de alteração, além do crescimento e diferenciação das depressões após exposição subaérea (Twidale \& Vidal Romaní, 2005).

\subsubsection{Tanques de origem polifásica}

Os tanques polifásicos subedáficos desenvolvem-se sob um perfil edáfico, sendo o resultado do avanço irregular da frente de alteração e do acúmulo de umidade na base do material inconsolidado que constitui o regolito (Twidale, 1989, 
2002; Vidal Romaní, 1989; Vidal Romaní \& Twidale, 1998). As águas que percolam em subsuperfície tendem a aproveitar as zonas de debilidade presentes no embasamento cristalino sob o manto de intemperismo (Twidale, 1989). Geralmente as zonas preferenciais ao ataque intempérico e corrosão química possuem composição mineralógica diferenciada, por exemplo, os xenólitos ou autólitos (enclaves) e em diques. As variações texturais da rocha também representam um outro fator condicionante, juntamente com os sistemas de juntas e fraturas existentes no arcabouço geológico. Ao remover a cobertura sedimentar, o material que foi retrabalhado em subsuperfície tende a ser exumado e as formas, resultantes da corrosão química, são denominadas como formas etch. Entre as inúmeras formas desenvolvidas, destacam-se os tanques naturais sobre o embasamento cristalino.

Assim, o processo de corrosão química responsável pela formação dos tanques polifásicos subedáficos evoluem em duas etapas (Fig. 7). A primeira refere-se ao modelado da frente de alteração segundo os fatores referidos anteriormente: o controle litológico e/ou estrutural em subsuperfície. Segundo Twidale (1989), essa etapa sempre tem lugar em condições subterrâneas, ou seja, por debaixo da superfície e livre das condições atmosféricas. A segunda etapa implica na denudação do regolito e a exposição da frente de alteração. Geralmente o trabalho remontante da drenagem tende a remover o regolito; no entanto, a denudação pode ser realizada, com resultados semelhantes, por exemplo, pela ação direta de ondas, próximo ao ambiente costeiro, e por ação do vento, em um ambiente de deflação (Twidale, 1989). Na maior parte das vezes quando a forma, no caso o tanque natural, é exposto à superfície, o material rochoso perde o contato com o regolito, ou seja, o tanque deixa de manter uma área umedecida onde atua a frente de alteração na rocha e permanece relativamente seco e estável. Segundo Mayor Rodriguez (2011) os tanques polifásicos subedáficos seguem evoluindo ao receber o aporte de água meteórica e, geralmente, a forma inicial é uma morfologia do tipo fundo plano.
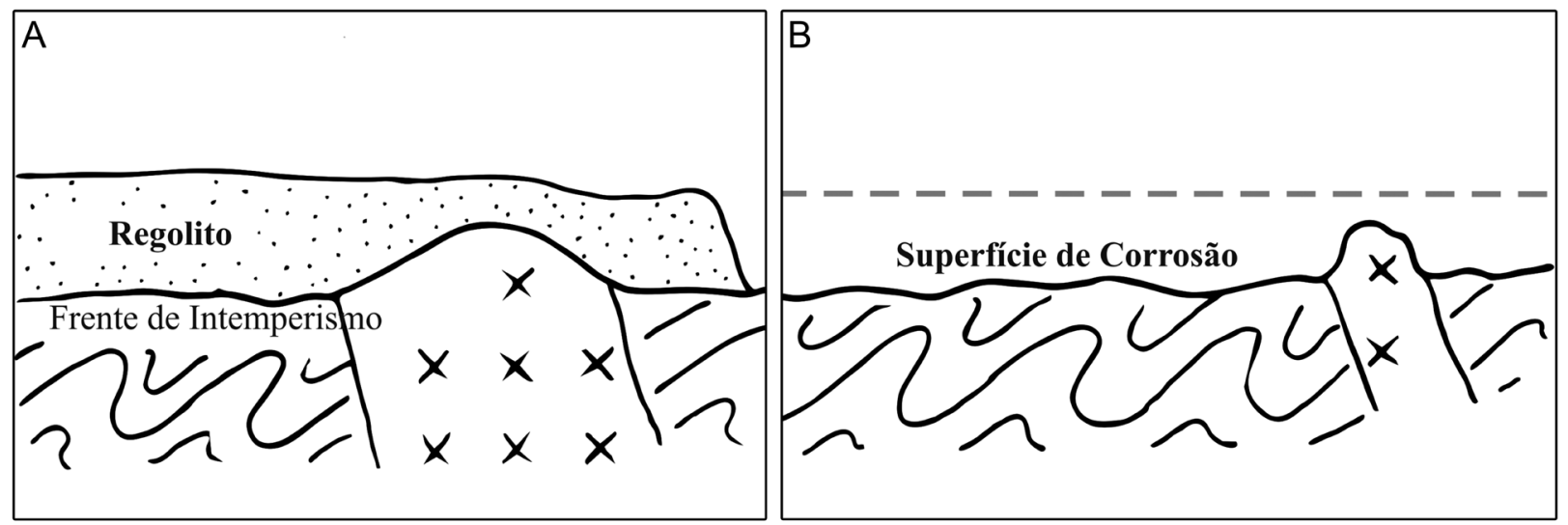

Figura 7. Diagrama das relações entre o regolito, frente de intemperismo e as formas de etchplain resultantes da corrosão química em subsuperfície. A) Etapa 1, embasamento cristalino recoberto pelo regolito; B) Etapa 2, exposição das formas moldadas em condições subedáficas (modificado de Twidale, 1989).

Figure 7. Diagram showing relationships between regolith, weathering front and etch forms resulting from chemical subsurface corrosion. A) Stage 1, crystalline bedrock covered by regolith; B) Stage 2, exposure of forms shaped in subedaphic conditions (modified from Twidale, 1989).

0 modelo de tanque polifásico gerado em condições subedáficas possivelmente desempenha o mais importante papel na origem e desenvolvimento de tanques naturais em áreas próximas de inselbergs no Nordeste brasileiro. A formação dessas depressões seria o resultado de um processo de corrosão química prolongado em subsuperfície, sendo posteriormente exposto. 0 desenvolvimento de sistemas de fraturas/diáclases pode ser associado à atuação de processos geológicos internos, sendo originado durante o resfriamento de um magma e/ou durante fases de deformação de caráter rúptil ou por meio de eventos atectônicos, como por exemplo, as fraturas de alívio de tensão, originadas pela expansão da rocha em direção a superfície, resultante da redução da pressão confinante após o soerguimento e/ou erosão das camadas sobrejacentes (Fernandes \& Amaral, 2006). Geralmente em grandes profundidades (dezenas de quilômetros), as fraturas correspondem às principais movimentações rúpteis, e posteriormente por alívio de tensão, sobre o embasamento cristalino durante o extenso tempo geológico na Plataforma Sul-americana, nesse caso, na Província Borborema. Esses conjuntos de sistemas de fraturas, uma vez alcançados pela frente de in- 
temperismo sob o manto regolítico - atualmente, alcançando dezenas de metros de espessura, mas pode chegar a maiores profundidades em regiões equatoriais úmidas -, iniciaram o desenvolvimento dos tanques naturais reaproveitando a interseção de fraturas. 0 modelo interpreta que a origem e o desenvolvimento dos tanques naturais, através da corrosão química em subsuperfície, pode ter iniciado em período de tempo muito anterior ao Pleistoceno Final, discordando, portanto, do tempo previamente sugerido por Oliveira \& Hackspacher (1989) para a origem dessas depressões.

As oscilações climáticas durante o Quaternário, principalmente durante o Pleistoceno Final, podem ter contribuído para a remoção do restante do regolito que recobria o embasamento cristalino, dessa maneira, expondo os tanques naturais já desenvolvidos às condições subaéreas. É provável que durante o período de remoção do regolito, o material in situ que preenchia as cavidades foi também parcialmente removido. Posteriormente, os tanques naturais tiveram importante papel como área de confluência de fluxos e materiais, sendo ocasionalmente preenchidos por restos fósseis trazidos pelo escoamento superficial. Os tanques naturais atualmente expostos seguem seu desenvolvimento em ambiente subaéreo.

Os tanques polifásicos gerados por concentração de cargas também são formados em condições subedáficas. No entanto, o modelo baseia-se na aplicação de força, induzida pela migração e concentração de cargas, em áreas específicas do embasamento cristalino. A força exercida em determinados pontos resulta em deformações elásticas internas que, ao longo do tempo geológico, podem se tornar permanentes (Vidal Romaní, 1989). Esses pontos específicos de contato se configuram em zonas suscetíveis e preferenciais ao ataque intempérico, tanto em subsuperfície como em condições subaéreas. Os tanques gerados por concentração de cargas são formados por duas vias distintas, mas levam ao mesmo tipo de efeito. São chamadas: via gravitacional e a via tectônica (Vidal Romaní, 1989; Vidal Romaní \& Twidale, 1998; Vidal Romaní \& Yepes Termiño, 2004; Twidale \& Vidal Romaní, 2005).

A via gravitacional coincide com o processo de alteração de um determinado maciço rochoso segundo o sistema ortogonal de fraturas e descontinuidades. Esse efeito contínuo de espessamento do material intemperizado, ou desenvolvimento do regolito, resulta no processo denominado migração de cargas (Vidal Romaní, 1989; Vidal Romaní \& Twidale, 1998; Vidal Romaní \& Yepes Termiño, 2004; Twidale \& Vidal Romaní, 2005). O processo baseia-se em uma troca no sistema de apoio entre os blocos graníticos subjacentes, separados por uma descontinuidade ao longo da qual a percolação da água tenha produzido a alteração da rocha. Segundo Vidal Romaní (1989), esse processo de meteorização não é homogêneo, mas desigual no plano de descontinuidade. 0 contato entre os blocos pode variar, incluindo contatos através de um material intemperizado de maior ou menor espessura, ou contatos diretos entre a rocha sã com a rocha sobrejacente (Fig. 8). Desta forma, o peso que inicialmente se encontrava distribuído ao longo de toda a superfície entre os dois blocos, vai de maneira contínua concentrando nos pontos onde ainda segue o contato entre rochas.
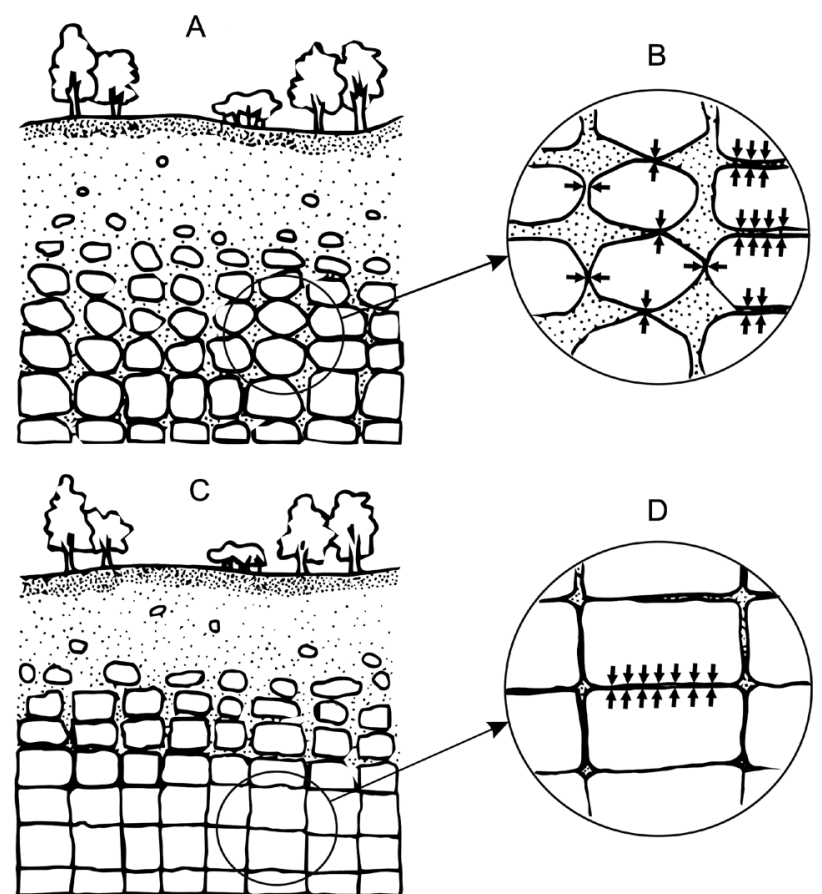

Figura 8. 0 processo de migração e concentração de cargas por alteração via gravitacional, o desenvolvimento do regolito a favor de diferentes sistemas de descontinuidades. A-B) Distribuição concentrada de cargas litostáticas; e C-D) Distribuição uniforme de cargas litostáticas (modificado de Vidal Romaní \& Yepes Termiño, 2004).

Figure 8. The process of migration and concentration of charges by gravitational alteration, the development of regolith in favor of the different discontinuity system. A-B) Concentrated distribution of lithostatic charges; $C$-D) Concentrated distribution of lithostatic charges (modified from Vidal Romaní \& Yepes Termiño, 2004).

De acordo com Vidal Romaní \& Yepes Termiño (2004), a migração de cargas pode ser entendida melhor em uma comparação com o faquir indiano em seu leito de pregos. Compreende-se perfeitamente como aumenta o desconforto do faquir à medida que se vai retirando progressivamente mais pregos de seu colchão, incrementando o peso que gravita sobre os pregos remanescentes. 0 mesmo tipo de efeito ocorre com um maciço 
rochoso quando as rochas se meteorizam em seu entorno, aplicando a migração de cargas sobre os blocos definidos pelo sistema de descontinuidades. 0 chamado "efeito faquir" faz com que o peso do bloco e de sua reação varie desde uma distribuição homogênea em todo contorno até que, com o avanço da meteorização, se concentre em alguns poucos pontos onde a rocha ainda continua intacta (Vidal Romaní, 1989; Vidal Romaní \& Twidale, 1998).

Segundo Twidale \& Vidal Romaní (2005) esse efeito de migração e concentração de cargas pode produzir um aumento de até 100 ou 1000 vezes na magnitude da carga suportada pela rocha. Em trabalhos anteriores (Vidal Romaní, 1989; Vidal Romaní \& Yepes Termiño, 2004) calculou-se que a uma profundidade de cerca de $300 \mathrm{~m}$ se pode alcançar as condições para que a rocha se plastifique nas imediações desses pontos de contato. A consequência imediata desse efeito é uma distorção na estrutura mineral da rocha e da própria desagregação interna do bloco, convertendo esses pontos em áreas mais suscetíveis ao ataque intempérico (Figs. 9 e 10). A partir das formas côncavas definidas pela deformação elástica, tanques podem vir a serem desenvolvidos em planos de contatos horizontais. Entretanto, se os planos de contato forem verticais a subverticais, ou a desagregação do material ocorrer no bloco superior, as formas resultantes podem ser os taffoni (Vidal Romaní \& Twidale, 1998).

A via tectônica é considerada o segundo meio de formação de cavidades gerados pelo processo de concentração de cargas (Vidal Romaní \& Twidale, 1998). Neste caso, o tectonismo tem função dominante sobre o maciço granítico fraturado e no processo de concentração de cargas. Os movimentos resultantes de soerguimentos e abaulamentos regionais podem gerar ou restabelecer o contato entre superfícies rochosas, por exemplo, entre os blocos pré-estabelecidos pertencentes ao sistema de descontinuidades do maciço. Ao redor dos pontos de contato, entre os blocos rochosos ou das descontinuidades são estabelecidos os novos pontos de deformação elástica. 0 efeito é novamente uma distorção na estrutura mineral da rocha e desagregação interna do bloco, convertendo esses pontos em zonas preferenciais de meteorização. De acordo com Vidal Romaní \& Twidale (1998), é necessário a existência de um sistema prévio de descontinuidades e fraturas aberto para que esse tipo de processo ocorra.
Entre as vias estabelecidas, a via tectônica talvez seja a que receba maior atenção em relação aos processos de formação e distribuição de tanques naturais expostos na paisagem nordestina. Segundo Bezerra \& Vita-Finzi (2000), diversos indicadores como, por exemplo, de controle estrutural da drenagem, estruturas de liquefação nos sedimentos fluviais e a presença de deformações e falhas em pacotes de rochas do período Neógeno evidenciam as atividades tectônicas de caráter pós-pliocênico no Nordeste do Brasil. A neotectônica pode apresentar dupla função para os tanques naturais. A primeira refere-se que os movimentos associados ao tectonismo tendem a alcançar mais facilmente, e em escala regional, os valores para as tensões aplicadas entre os pontos de contato. Assim, o processo de concentração de cargas definiria inúmeras zonas de debilidade, deformadas elasticamente e suscetíveis à alteração intempérica. E a segunda função seria a própria exposição dos tanques naturais, pré-estabelecidos ou com determinado grau de desenvolvimento a condições subaéreas, resultantes do soerguimento e abaulamento do mosaico tectônico nordestino.

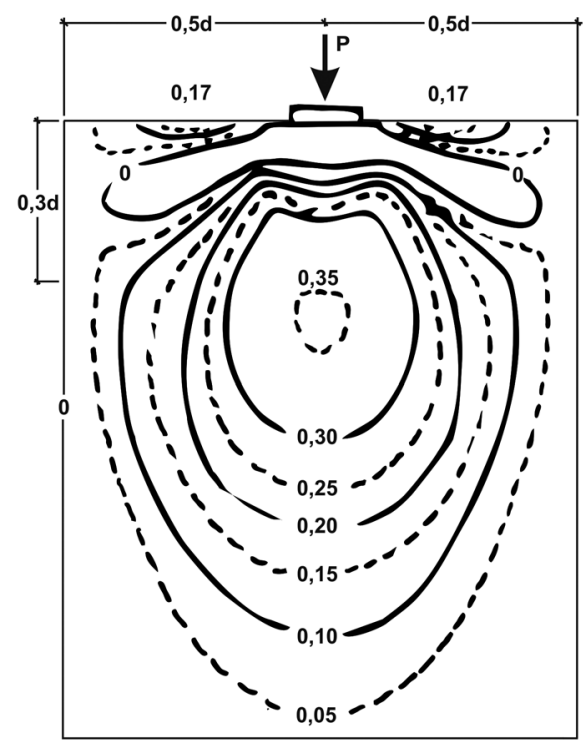

Figura 9. Esquete da zona deformada internamente sob a concentração de tensões P. 0 domínio inclui a linha contínua 0 , que corresponde à área onde localiza-se a compressão. 0 restante da rocha, entre as linhas 0,05 e 0,35, corresponde à área onde eventualmente se desenvolvem as cavidades taffone ou gnamma (modificado de Twidale \& Vidal Romaní, 2005). Figure 9. Sketch of the deformed zone under a concentrated $P$ charge. The domain included the continuous line 0 , corresponds to the area located at compression. The rest of the rock, between 0.05 and 0.35 , corresponds to an area that would eventually evolve towards a taffone or a gnamma (modified from Twidale \& Vidal Romaní, 2005). 

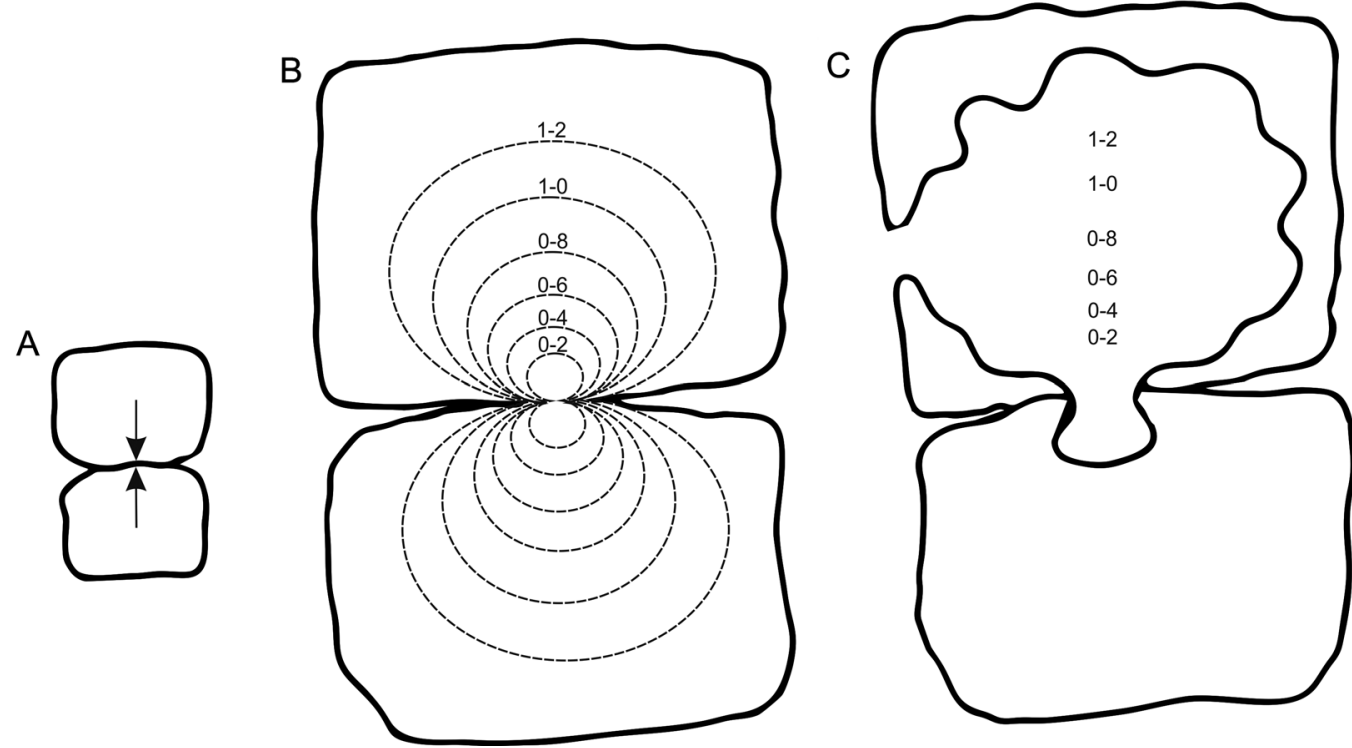

Figura 10. Evolução esquemática do tanque natural e taffone. A) Zona de contato entre dois blocos ao longo de uma fratura; B) Concentração de cargas; C) Formas finais resultantes. As linhas concêntricas indicam o fator de segurança (modificado de Vidal Romaní \& Twidale, 1998).

Figure 10. Schematic evolution of natural tank and taffone. A) Zone of contact between two blocks along a fracture; B) Charges concentrations; C) Resultant forms. The figures indicate stability coefficient (modified from Vidal Romaní \& Twidale, 1998).

\section{Conclusões}

Os tanques naturais representam hoje uma importante feição geomorfológica em terrenos cristalinos no Nordeste do Brasil. Os levantamentos iniciais elaborados pelas expedições científicas no início e metade do século XIX tinham como função prioritária o resgate do importante conteúdo fossilífero dessas pequenas depressões colmatadas de sedimentos do Quaternário. Entre o pioneiro trabalho de Hartt, em 1870, e as propostas elaboradas no início do Século XX, passaram-se praticamente 40 anos sem novos trabalhos sobre a possível formação dos tanques naturais na região nordeste do Brasil. A partir de 1920 até 1990 um grande número de trabalhos começou a ser elaborado afim de compreender a origem dos tanques naturais. Entretanto, as hipóteses elaboradas baseavam-se exclusivamente em processos físicos e, posteriormente químicos, sob condições subaéreas. Apesar das diferentes interpretações sobre o principal tipo de controle na formação da cavidade, como por exemplo, o controle estrutural, litológico, climático, biológico ou dinâmico, os trabalhos anteriores aos anos 80 seguiam basicamente a hipótese do trabalho de evorsão no leito rochoso dos rios. Os trabalhos seguiram basicamente o modelo monofásico baseado no intemperismo físico-químico, em superfície, agindo de maneira diferencial sobre o conjunto de fraturas e diáclases no entorno de maciços rochosos.

A proposta do modelo polifásico baseia-se, principalmente, nas discussões a partir da década de 1990 e de trabalhos recentes elaborados na Espanha e Austrália, na ideia de processos em subsuperfície serem responsáveis por formas semelhantes tanto no Brasil como em outras partes do mundo, apesar de condições climáticas, topográficas e litológicas tão distintas. A gênese de tanques naturais no Nordeste do Brasil, ao contrário da necessidade da superfície estar exposta, para iniciar a formação da cavidade, os tanques polifásicos, teriam sua origem e desenvolvimento associado ao ambiente subedáfico. Os principais processos são de corrosão, feito a partir da frente de alteração do manto intempérico, agindo com maior eficiência em zonas de debilidade constituídas por um sistema de fraturas/diáclases/enclaves ou em zonas de debilidade pré-estabelecidas resultantes do efeito de migração e concentração de cargas. 0 modelo polifásico apresenta duas etapas diferentes para a formação do tanque, o primeiro estágio está relacionado ao processo em subsuperfície e, o segundo é associado à exposição subaérea, onde segue se desenvolvendo ou são destruídos ao longo do tempo.

O modelo de tanques polifásicos constitui uma via de compreensão ao tema sobre formação de tanques naturais no Nordeste do Brasil. No entanto, não substitui ou elimina o modelo monofásico, sendo uma complementação aos estudos sobre tanques brasileiros. Ambos os modelos podem ocorrer na paisagem do Nordeste brasileiro, configurando em variedade de formas que seguem sua evolução através do tempo geológico. A padronização da terminologia aqui proposta permitirá 
estabelecer relações entre aspectos morfológicos de estruturas análogas, aqui denominadas como tanques naturais (stricto sensu), em diferentes continentes.

Agradecimentos. À Coordenação de Aperfeiçoamento de Pessoal de Nível Superior (CAPES) pelo apoio financeiro; à equipe da biblioteca do Centro de Tecnologia e Ciência (CTC/C) e ao Núcleo de Memória, Informação e Documentação (MID) da Universidade do Estado do Rio de Janeiro (UERJ) pelo auxílio na pesquisa documental e disponibilização das obras utilizadas; a Juan Ramón Vidal Romaní, do Instituto Universitario de Geología Isídro Parga Pondal, da Universidad de Coruña - Espanha, pela análise crítica deste manuscrito; a Celso Lira Ximenes por gentilmente ceder as figuras 4, 6A e 6C; aos revisores anônimos e ao editor adjunto pelas críticas e comentários os quais permitiram o aprimoramento deste manuscrito.

\section{Referências}

Alkmim, F.F. 2004. 0 que faz de um cratón um cratón? 0 Cratón do São Francisco e as revelações almedianas ao delimitá-lo. In: Mantesso-Neto, V, Bartorelli, A., Carneiro, C.D.R. \& Brito Neves, B.B. (Ed.). Geologia do Continente Sul-Americano: Evolução da Obra de Fernando Flávio Marques de Almeida. São Paulo, Editora Beca, p. 17-36.

Almeida, F.F.M., Hasuy, Y., Brito Neves, B.B. \& Fuck, R.A. 1981. Brazilian structural provinces: an introduction. Earth-Science Reviews, 17: 1-21.

Araújo-Júnior, H.I. 2016. Classifying vertebrate assemblages preserved in Quaternary tank deposits: Implications for vertebrate taphonomy and paleoecology. Palaeogeography, Palaeoclimatology, Palaeoecology, 445: 147-152.

Araújo-Júnior, H.I. \& Moura, G.J.B., 2014. Anuros (Amphibia, Anura) do Pleistoceno Final-Holoceno inicial de Itapipoca, Estado do Ceará, Brasil: Taxonomia, Paleoecologia e Tafonomia. Revista Brasileira de Paleontologia, 17: 373-388.

Araújo-Júnior, H.I. \& Porpino, K.O. 2011. Assembléias fossilíferas de mamíferos do Quaternário do Estado do Rio Grande do Norte, Nordeste do Brasil: diversidade e aspectos tafonômicos e paleoecológicos. Pesquisas em Geociências, 38: 67-83.

Araújo-Júnior, H.I., Porpino, K.O., Ximenes, C.L. \& Bergqvist, L.P. 2011. Análise multivariada como ferramenta tafonômica no estudo das associações quaternárias de mamíferos do Nordeste do Brasil. Gaea - Journal of Geoscience, 7: 104-111.

Araújo-Júnior, H.I., Porpino, K.O., Ximenes, C.L. \& Bergqvist, L.P. 2013a. Unveiling the taphonomy of natural tank deposits: a case study in the Pleistocene of northeastern Brazil. Palaeogeography, Palaeoclimatology, Palaeoecology, 378: 52-74.

Araújo-Júnior, H.I., Porpino K.O. \& Bergqvist, L.P. 2013b. Taphonomic analysis of a late Pleistocene vertebrate accumulation from Lage Grande Paleontological
Site, Pernambuco State, northeastern Brazil: New remarks on preservational aspects of tank deposits. Quaternary International, 317: 88-101.

Araújo-Júnior, H.I., Porpino, K.O. \& Bergqvist, L.P. 2015. Vertebrate taphonomy and paleoecology in an Upper Pleistocene tank deposit of Paraíba, Brazil: Taphonomic modes, evidence of temporal and spatial resolutions and paleoecological patterns of the Brazilian Intertropical Region. Palaeogeography, Palaeoclimatology, Palaeoecology, 437: 1-17.

Araújo-Júnior, H.I., Porpino, K.O., Bergqvist, L.P.\& Dardon, U. 2016. New fossil Record of Bufonidae (Amphibia, Anura) in the Late Pleistocene-early Holocene of Northeastern Brazil and its paleoenvironmental significance. Journal of Sedimentary Environments, 1(1): 68-77.

Archanjo, C.J., Hollanda, M.H.B.M., Rodrigues S.W.O., Brito Neves, B.B. \& Armstrong, R. 2008. Fabrics of pre and syntectonic granite plutons and chronology of shear zones in the Eastern Borborema Province, NE Brazil. Journal of Structural Geology, 30: 310-336.

Bergqvist, L.P., Gomide, M., Cartelle, C. \& Capilla, R. 1997. Faunas-locais de Mamíferos Pleistocênicos de Itapipoca/Ceará, Taperoá/Paraíba e Campina Grande/Paraíba. Estudo Comparativo, Bioestratinômico e Paleoambiental. Geociências, 2(6): 23-32.

Bezerra, F.H. \& Vita-Finzi, C. 2000. How active is a passive margin? Paleoseismicity in Northeastern Brasil. Geology, 28: 591-594.

Bigarella, J.J. 1994. Estrutura e origem das paisagens tropicais e subtropicais volume 1. Florianópolis, Editora da UFSC, 425p.

Branner, J.C. 1902. On the occurrence of fossil remains of mammals in the interior of the States of Pernambuco and Alagoas, Brazil. American Journal of Science,13: 133-137.

Branner, J.C. 1915. Geologia Elementar. Rio de Janeiro, Livraria Francisco Alves, 404p.

Branner, J.C. 1948. Da Ocorrência de Restos de Mamíferos Fósseis no Interior dos Estados de Pernambuco e Alagoas. Boletim Geográfico, 68: 941-943.

Brito Neves, B.B., Santos, E.J. \& Van Schmus, W.R. 2000. Tectonic history of the Borborema Province. In: Cordani, U.G., Milani, E.J., Thomaz Filho, A. \& Campo, D.A. (Ed.). Tectonic Evolution of the South America. Rio de Janeiro, Sociedade Brasileira de Geologia, p. 151-182.

Burlamaque, F.L.C. 1855. Notícia acerca dos animaes de raças extinctas descobertos em vários pontos do Brasil. Trabalhos da Sociedade Vellosiana, 20: 1-16.

Burlamaque, F.L.C. 1856. Notícia acerca dos animaes de raças extinctas descobertos em vários pontos do Brasil. Trabalhos da Sociedade Vellosiana, 20: 17-21.

Campbell, E.M. 1997. Granite Landforms. Journal of the Royal Society of Western Australia, 80(3): 101-112.

Campbell, E.M. \& Twidale, C.R. 1995. The various origins of minor granite landforms. Cadernos do Laboratorio Xeolóxico de Laxe (Coruña), 20: 281-306.

Cartelle, C. 1999. Pleistocene mammals of the Cerrado and Caatinga of Brazil. In: Eisenberg, J.F. \& Redford, K.H. (Ed.). Mammals of the Neotropics: The Central 
Neotropics. Chicago, The University of Chicago Press, p. 27-46.

Casal, M.A. 1817a. Corografia brazilica, ou Relação historico-geografica do Reino do Brazil. Rio de Janeiro, Impressão Régia, 182p.

Casal, M.A. 1817b. Corografia brazilica, ou Relação historico-geografica do Reino do Brazil. Rio de Janeiro, Impressão Régia, 158p.

Dantas, M.A.T., Zucon, M.H. \& Ribeiro, A.M. 2005. Megafauna pleistocênica da Fazenda Elefante, Gararu, Sergipe, Brasil. Geociências, 24: 277-287.

Domingues, A.J.P. 1952. Provável origem das depressões observadas no Sertão do Nordeste. Revista Brasileira de Geografia, 14(3): 65-75.

Faria, F.H.R., Ribeiro, R.C. \& Carvalho, I.S. 2013. Feições de intemperismo em fósseis da megafauna do Quaternário tardio de Lagoa do Rumos, Baixa Grande (BA), Brasil. Brazilian Journal of Geology, 43(1): 3747.

Fernandes, A.C.S., Fonseca, V.M.M. \& Henriques, D.D.R. 2007. Histórico da Paleontologia no Museu Nacional. Anuário do Instituto de Geociências, 30(1): 188-190.

Fernandes, A.C.S., Ewbank, C.O., Silva, M.J. \& Henriques, D.D.R. 2010. Uma lembrança de infância: os "fósseis colossais" e o papel de Frederico Leopoldo César Burlamaque como paleontólogo brasileiro. Filosofia e História da Biologia, 5(2): 239-259.

Fernandes, A.C.S., Ramos, R.R.C., Silva, J.L.L. \& Silva A.P.L. 2012. Do Nordeste para o Rio de Janeiro: os tanques das primeiras remessas de fósseis de megafauna enviadas ao Museu Nacional. In: SIMPÓSIO BRASILEIRO DE PALEONTOLOGIA DE VERTEBRADOS, 7, 2012, Recife. Boletim de Resumos. Recife, SBPV, Edição Especial, p. 63-63.

Fernandes, A.C.S., Ximenes, L.C. \& Antunes, M.T. 2013a. Na Ribeira do Acaraú João Batista de Azevedo Coutinho de Montaury e a descoberta documentada de megafauna no Ceará em 1784. Filosofia e História da Biologia, 8(1): 21-37.

Fernandes, A.C.S., Faria, F. \& Antunes, M.T. 2013b. Manuel Aires de Casal, o beemote de Jó e o registro das ocorrências fossilíferas brasileiras no início do século XIX. Filosofia e História da Biologia, 8(2): 133-150.

Fernandes, N.F. \& Amaral, C.P. 2006. Movimentos de Massa: Uma Abordagem Geológica Geomorfológica. In: Guerra, A.J.T. \& Cunha, S.B. (Ed.). Geomorfologia e Meio Ambiente. Rio de Janeiro, Bertrand Brasil, p. 123-194.

Hartt, C.F. 1870. Geology and Physical Geography of Brazil. Boston, Fields, Osgood \& C0, 620p.

Hartt, C.F. 1941. Geologia e Geografia Física do Brasil. São Paulo, Editora Nacional, 649p.

Mabesoone, J.M. \& Castro, C. 1975. Desenvolvimento geomorfológico do Nordeste brasileiro. Boletim do Núcleo Nordeste da Sociedade Brasileira de Geologia, 3: 5-36.

Mabesoone, J.M., Oliveira, L.D.D. \& Damasceno, J.M. 1990. Desenvolvimento dos Tanques Fossilíferos no Semi-árido Norteriograndense. In: CONGRESSO BRASILEIRO DE GEOLOGIA, 36., 1990, Natal. Anais... Natal, SBG, v. 2, p. 733-741.
Mayor Rodriguez, J.A. 2011. Génesis de Cavidades Graníticas en Ambientes Endógenos y Exógenos. La Coruña, 396p. Tesis Doctoral. Instituto Universitario de Geología Isidro Parga Pondal, Universidad de Coruña.

Moraes, L.J. 1924. Serras e Montanhas do Nordeste. Rio de Janeiro, Inspetoria Federal de Obras Contra as Secas, $120 \mathrm{p}$.

Moraes, L.J. 1928. Estudos Geológicos no Estado de Pernambuco. Boletim do Serviço Geológico e Mineralógico do Brasil, 32:1-98.

Moraes Rêgo, L.F. 1926. O Reconhecimento Geológico da parte ocidental do Estado da Bahia. Boletim do Serviço Geológico e Mineralógico do Brasil, 17: 33-54.

Oliveira, E.V., Barreto, A.M.F. \& Alves, R.S. 2009. Aspectos sistemáticos, paleobiogeográficos e paleoclimáticos dos mamíferos quaternários de Fazenda Nova, PE, Nordeste do Brasil. Gaea - Journal of Geoscience, 5: 75-85.

Oliveira, L.D.D. 1989. Considerações sobre o emprego da terminologia da "formação cacimbas" e caldeirões para os tanques fossilíferos do nordeste do Brasil. In: CONGRESSO BRASILEIRO DE PALEONTOLOGIA, 11., 1989, Curitiba. Anais... Curitiba, SBP, v.1, p. 535-539.

Oliveira, L.D.D. \& Hackspacher, P.C. 1989. Gênese e provável idade dos tanques fossilíferos de São Rafael-RN. In: CONGRESSO BRASILEIRO DE PALEONTOLOGIA, 11., 1989, Curitiba. Anais... Curitiba, SBP, v. 1, p. 541-549.

Oliveira, L.D.D., Damasceno, J.M., Lins, F.A.P.L., Medeiros, W.E. \& Moreira, J.A. 1989. Estudo Macrofossilífero dos Tanques da Fazenda Capim Grosso, São Rafael RN, Auxiliado por métodos geofísicos. In: CONGRESSO BRASILEIRO DE PALEONTOLOGIA, 11., 1989, Curitiba. Anais... Curitiba, SBP, v.1, p. 551-563.

Paula-Couto, C. 1953. Paleontologia Brasileira: Mamíferos. Rio de Janeiro, Instituto Nacional do Livro, 516p.

Paula-Couto, C. 1980. Fossil Pleistocene to sub-recent mammals from northeastern Brazil. I-Edentata Megalonychidae. Anais da Academia Brasileira de Ciências, 52(1): 144-151.

Pedraza, J.G. 1996. Geomorfología: Principios, Métodos y Aplicaciones. Madrid, Editorial Rueda, S. L, 414 p.

Rodrigues, S.W.O., Archanjo, C.J. \& Grohmann, C.H. 2010. Quantificação da Deformação Finita nos Metagranitoides Cariris Velhos na Região de Alagoa Grande (PB). Geologia USP - Série científica, 10(3): 57-78.

Ribeiro, R.C. 2014. Assembléia fossilífera do Quaternário tardio de Lagoa do Rumo, Baixa Grande, Bahia: Tafonomia e Geocronologia. Rio de Janeiro, 150 p. Tese de Doutorado, Programa de Pós-graduação em Geologia, Instituto de Geociências, Universidade Federal do Rio de Janeiro.

Rolim, J.L. 1974. Paleontologia e Estratigrafia do Pleistoceno continental do Nordeste Brasileiro "Formação Cacimbas". Porto Alegre, 117p. Dissertação de Mestrado, Programação de Pós-graduação em Geociências, Instituto de Geociências, Universidade Federal do Rio Grande do Sul.

Rolim, J.L. 1982. Pesquisas de Mamíferos Pleistocênicos no Nordeste Brasileiro. Coleção Mossoroense, 183: 
5-11.

Santos, M.F.C.F., Bergqvist, L.P., Lima-Filho, F.P. \& Pereira, M.M.V. 2002. Feições tafonômicas observadas em fósseis pleistocênicos do Rio Grande do Norte. Revista de Geologia, 15: 31-41.

Santos, R.S. 1982. Fauna Cenozóica da Região Nordeste do Brasil. Coleção Mossoroense, 15 (233): 1-141.

Silva, F.M. 2014. Tafonomia em tanque de Fazenda Nova, município de Brejo da Madre de Deus, Estado de Pernambuco, Nordeste do Brasil. Recife, 105p. Tese de Doutorado. Programa de Pós-graduação em Geociências, Instituto de Geologia. Universidade Federal de Pernambuco.

Silva, J.L.L. 2008. Reconstrução paleoambiental baseada no estudo de mamíferos pleistocênicos de Maravilha e Poço das Trincheiras, Alagoas, Nordeste do Brasil. Recife, 213p. Tese de Doutorado. Programa de Pós-graduação em Geociências, Instituto de Geologia. Universidade Federal de Pernambuco.

Spix, J.B.V. \& Martius, K.F.P.V. 1824. Travels in Brazil in the years 1817-1820. London, A. \& R. Spottiswoode, 298p.

Spix, J.B.V. \& Martius, K.F.P.V. 1928. Reise in Brasilien in den Jahren 1817 bis 1820. München, I.J. Lentner, 468p.

Spix, J.B.V. \& Martius, K.F.P.V. 1968. Viagem pelo Brasil: 1817-1820. São Paulo, Edições Melhoramentos, $332 p$.

Teixeira W., Sabaté P., Barbosa J.S.F., Noce C.M. \& Carneiro M.J. 2000. Archean and paleoproterozoic tectonic evolution of the São Francisco Cráton. In: Cordani, U.G., Milani, E.J., Thomaz Filho, A. \& Campos, D.A. (Ed.). Tectonic Evolution of South America. Rio de Janeiro, Sociedade Brasileira de Geologia, p. 101-138.

Twidale, C.R. 1968. Origin of Wave Rock, Hyden, Western Australia. Transactions of the Royal Society of South Australia, 92: 115-123.

Manuscrito 644

Editores: Cesar L. Schultz \& Paulo A. Souza
Twidale, C.R. 1989. La iniciación subsuperficial de las formas graníticas y sus implicaciones en las teorías generales de evolución del paisaje. Cadernos do Laboratorio Xeolóxico de Laxe (Coruña), 13:49-68.

Twidale, C.R. 2002. The two-stage concept of landform and landscape development involving etching: origin, development and implications of an idea. Earth-Science Reviews, 57: 37-74.

Twidale, C.R. \& Campbell, E.M. 2005. Australian Landforms: Understanding a low, flat, arid and old landscape. Kenthurst, New South Wales, Rosenberg Publishing, 336p.

Twidale, C.R. \& Vidal Romaní, J.R. 2005. Landforms and Geology of Granitic Terrains. Leiden, Balkema, 352p.

Vidal Romaní, J.R. 1989. Geomorfología Granítica en Galicia (NW España). Cadernos do Laboratorio Xeolóxico de Laxe (Coruña), 13: 89-163.

Vidal Romaní, J.R. \& Twidale, C.R. 1998. Formas y Paisajes Graníticos. La Coruña, Universidad da Coruña Servicio de Publicaciones, 411p.

Vidal Romaní, J.R. \& Yepes Termiño, J. 2004. Historia de La Morfogénesis Granítica. Cadernos do Laboratorio Xeolóxico de Laxe (Coruña), 29: 331-360.

Ximenes, C.L. 2003. Proposta metodológica para um programa de micro-reservatórios alternativos de água nos sertões semi-áridos brasileiros, associado ao resgate de fósseis. Fortaleza, 146p. Dissertação de Mestrado. Programa de Pós-graduação em Geologia, Instituto de Geologia. Universidade Federal do Ceará.

Ximenes, C.L. 2009. Tanques Fossilíferos de Itapipoca, CE: Bebedouros e cemitérios de megafauna pré-histórica. In: Winge, M., Schobbenhaus, C., Souza, C.R.G., Fernandes, A.C.S., Berbert-Born, M., Queiroz, E.T., Campos, D.A. (Ed.). Sítios Geológicos e Paleontológicos do Brasil: SIGEP - Comissão Brasileira de Sítios Geológicos e Paleobiológicos. Brasília, p. 465-478. 
